\title{
A Cost-Benefit Methodology for Selecting Analytical Reinforced Concrete Corrosion Onset Models
}

\author{
N. Rakotovao Ravahatra, ${ }^{1,2}$ T. de Larrard, ${ }^{2}$ F. Duprat, ${ }^{2}$ E. Bastidas-Arteaga $\mathbb{D}^{1}$, \\ and F. Schoefs ${ }^{1}$ \\ ${ }^{1}$ Université de Nantes, Research Institute in Civil and Mechanical Engineering (GeM), UMR CNRS 6183, Nantes, France \\ ${ }^{2}$ Université de Toulouse, UPS, INSA, Materials and Durability of Constructions Laboratory (LMDC), Toulouse, France \\ Correspondence should be addressed to E. Bastidas-Arteaga; emilio.bastidas@univ-nantes.fr
}

Received 12 December 2019; Revised 20 May 2020; Accepted 15 June 2020; Published 7 August 2020

Academic Editor: Zhongguo John Ma

Copyright ( 92020 N. Rakotovao Ravahatra et al. This is an open access article distributed under the Creative Commons Attribution License, which permits unrestricted use, distribution, and reproduction in any medium, provided the original work is properly cited.

This work focuses on predicting corrosion onset induced by concrete carbonation or chloride ingress when using analytical predictive models. The paper proposes a procedure that helps building and infrastructure managers to select an appropriate model depending on the available information and the means granted to auscultation campaigns. The approach proposed combines the costs of input parameters, their relative importance, the benefits brought through obtaining parameters, and the maintenance strategy of the manager. Costs represent the intellectual investment to obtain parameters. This encompasses the time spent to obtain and analyze a result and the required expertise. Relative importance and benefits are obtained from sensitivity analysis. The effect of the maintenance strategy is introduced through a scalar called efficiency of the model. The proposed methodology is illustrated with two case studies where it is supposed that more or less extended information is available. Three concrete qualities are also considered in the case studies. The results highlight that the available data and concrete type have significant impacts on the selection of the most appropriate model.

\section{Introduction}

It is widely accepted that a suitable maintenance strategy helps to lengthen the service life cycle of structures [1]. Corrosion of steel is known as one of the phenomena that significantly reduces the life cycle of reinforced concrete structures $[2,3]$ increasing failure risks [4]. Some studies have been conducted to improve maintenance strategies against this pathology and taking into account uncertainties [5-11].

The theory of value of information (VoI) shows how information could improve the performance of a given system $[12,13]$. Some other studies considered expected value of perfect information (EVPI) such as Daneshkhah et al. [14] and Zitrou et al. [15]. Within a maintenance strategy, the prediction of the evolution along time of the degradation provided by models is an unavoidable crucial information. Indeed, this is necessary for helping to schedule repair or maintenance actions [16]. On the contrary, obtaining the values of input parameters could involve more or less important financial resources. Depending on their strategies, managers would not be willing to pay the same amount to obtain such model parameters. Consequently, in order to provide better help to managers for decision-making, quantification of benefits brought by obtaining parameters and hence using a given model should be provided.

A selection of degradation models is required for some purposes. First, models must be user-friendly (complex finite element models for instance are not always convenient for the daily practice of building managers, and their use is rather intended for specific problems). Second, the owners of structures and engineers working for them are prone to use models presented in standards and recommendations because these are generally recognized by insurance companies. Third, the prediction of carbonation and chloride ingress is improved by accounting for the uncertainties related to material properties, exposure, and specific 
adjusting factors. Then, the models should be able to propagate these uncertainties in a comprehensive way. Finally, the benefits brought by using the model must commensurate with the resources required for its use. Consequently, models must be able to propagate uncertainties, provide relevant results from a physical viewpoint, be updated especially from auscultations by nondestructive techniques, and provide a good cost/benefit ratio.

Within this framework, this paper proposes a procedure for comparing and selecting analytical carbonation models. The procedure combines (i) a sensitivity analysis that aims at quantifying the relative importance of each parameter and the ability of the models for propagating uncertainties [17] and (ii) an effectiveness analysis that integrates the cost required for estimating input parameters of the models. The objective is to provide a relevant tool for advising owners and managers in the choice of an appropriate model, with respect to the available maintenance resources.

The paper is organized as follows: in Section 2, we present the models and the main results of sensitivity analysis; in Section 3, we detail the structure and materials studied; and the methodology for the assessment of costs, benefit, and efficiency for each model and study case is detailed and illustrated in Sections 4, 5, and 6, respectively.

\section{Summary of the Methodology}

We provide in the current section a summary of the methodology. It is illustrated in the flowchart in Figure 1. This methodology could be applied to other degradation processes and is summarized by the following steps:

(1) To collect initial information concerning the degradation process and maintenance strategy: (i) degradation processes to be studied, (ii) data concerning the structure studied, and (iii) economical strategy of the building manager.

(2) To identify the existing models able to describe the degradation.

(3) For each degradation model, to identify all possible methods for determining each input parameter: expert assessment or by carrying out nondestructive or semidestructive testing.

(4) To assess the cost of each model:

(a) According to information obtained from previous step (step 3), to determine the cost (installation, workforces, etc.) of each input parameter of each model.

(b) Using the cost of parameters to compute costs for each model.

(5) To define realistic ranges of input parameter. This may require important literature review, as presented in a previous study [18]. This is useful for the following:

(a) Carry out sensitivity analysis (see step 6).

(b) Avoid unconsistent values when identifying inputs: in some practical cases, models are used to identify inputs using measurements of outputs (e.g., Bayesian inference). This was not the case in the current study. However, in such situations, compensations could appear between inputs resulting from the identification process, especially when model has too many parameters. This leads to unconsistent values. Parameters should hence be identified into realistic imposed ranges of values.

(6) To quantify the relative importance of each parameter of the models using sensitivity analysis: in the current study, we used various sensitivity indicators in order to have further information concerning the model behaviour [17].

(7) To compute the benefit for each model as follows:

(a) Using the results of the sensitivity analysis to estimate the improvement of the prediction of the model studied when obtaining a given parameter.

(b) Using the previous information to estimate the benefit of each model.

(8) In parallel with all previous steps, we characterize the maintenance strategy of the building manager: is the manager prone to invest importantly, poorly, or nothing at all for auscultation (nondestructive or semidestructive testing) campaigns?

(9) To identify which parameters could be supplied through auscultations given the strategy and financial resources of the manager.

(10) To compute the efficiency of each model by combining (i) model cost, (ii) benefit of model, and (iii) the financial strategy of the building manager.

(11) To compare the efficiencies of models by combining the previously mentioned factors and then to select the one which has the highest efficiency.

\section{Models and Sensitivity Analysis}

This section provides an overview of some models and sensitivity analysis results from a previous work [17] that are useful for the understanding of some trends in outcomes highlighted in the current paper.

3.1. Summary of Analytical Models. The analytical concrete carbonation and chloride ingress models collected in this work are summarized in Table 1 . The notations used for these models are also given in this table. These input parameters can be gathered at three levels (Figure 2 and Table 2).

3.1.1. Chloride Ingress Models. The chloride ingress models can be classified into two groups: (i) models without timedependent parameters and (ii) models with time-dependent parameters. These models are expressed according to the following equation: 


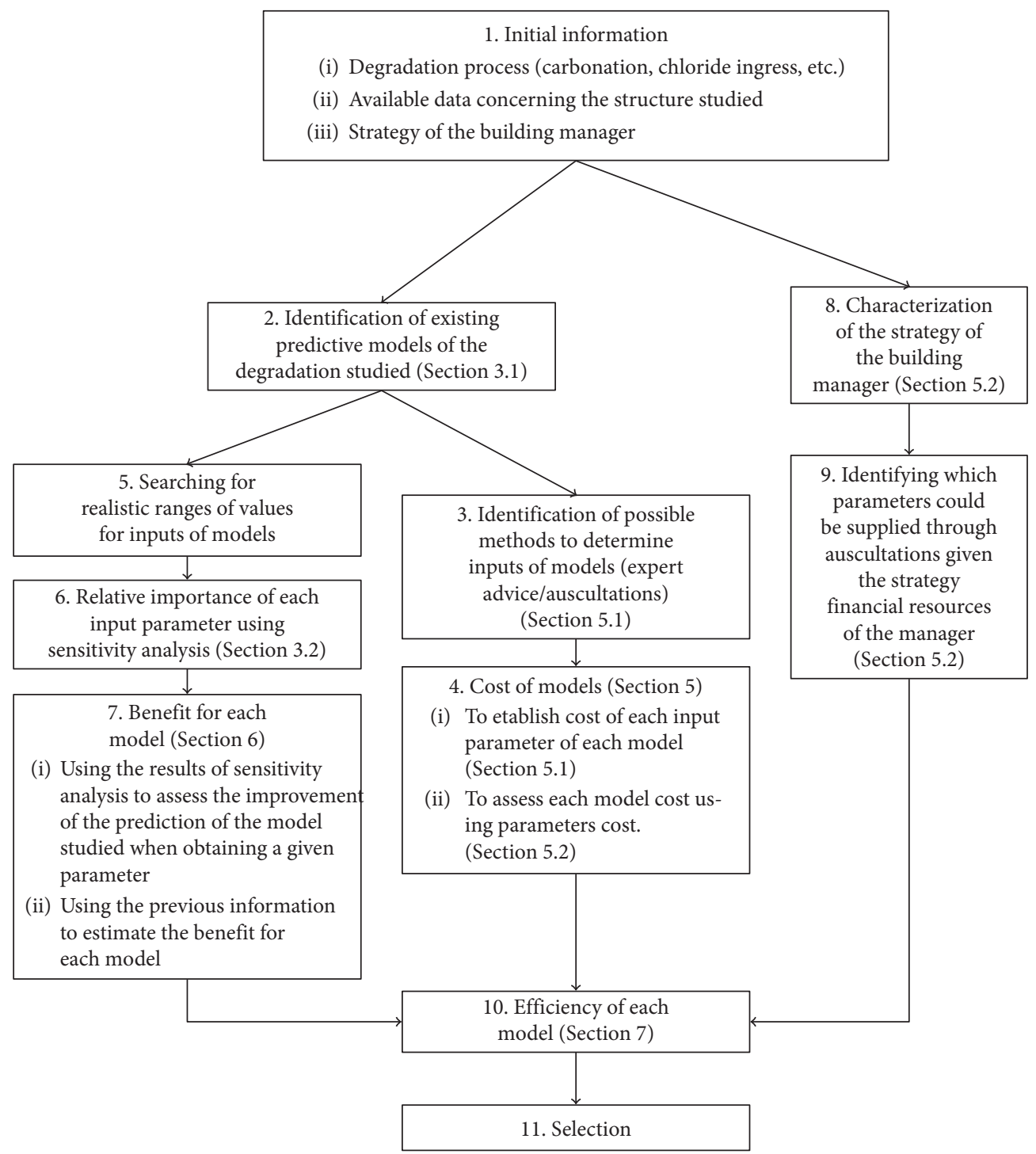

FIgURE 1: Flowchart of the method.

TABle 1: Analytical models of concrete carbonation and chloride ingress.

\begin{tabular}{lc}
\hline Model & Notation \\
\hline Chloride ingress & \\
Collepardi et al. [19] & Col \\
JSCE [20] & JSCE \\
Petre-Lazar [21] & LEO \\
EuroLightCon [22] & Eur \\
DuraCrete [23] & $\mathrm{Du}$ \\
Tang and Gulikers [24] & $\mathrm{Lu}$ \\
\hline Carbonation & \\
Ying-Yu and Qui-Dong [25] & $\mathrm{Yi}$ \\
Papadakis et al. [26] & $\mathrm{Pa}$ \\
CEB [27] & $\mathrm{CE}$ \\
DuraCrete [23] & $\mathrm{Du}$ \\
Miragliotta [28] & $\mathrm{Mi}$ \\
Petre-Lazar [21] & $\mathrm{Ox}$ \\
Hyvert [29] & $\mathrm{Hy}$ \\
\hline
\end{tabular}

$$
C(x, t)=C_{s} \operatorname{erfc}\left(\frac{x}{2 \sqrt{\xi(\mathbf{X}, t)}}\right)+C_{\mathrm{ini}},
$$

where $C(x, t)$ is the chloride content (\% wt. of concrete or \% wt. of binder) at distance $x$ from the concrete surface (m) and at time $t(\mathrm{~s}), C_{s}$ is the chloride content at the concrete surface that could be constant or time-dependent (\% wt. of concrete or $\%$ wt. of binder), and $\xi(\mathbf{X}, t)$ is a general function of concrete diffusivity, which depends on a vector $\mathbf{X}$ of input parameters that are specific to each model and the time $t(\mathrm{~s})$; depending on the models, concrete diffusivity could be constant or time-dependent, and $C_{\text {ini }}$ is the initial chloride content of the concrete (\% wt. of concrete or \% wt. of binder). The expressions of $\xi(\mathbf{X}, t)$ for each model are detailed in [17]. Table 3 presents the input parameters $\mathbf{X}$ for each studied chloride ingress model.

3.1.2. Concrete Carbonation Models. These models can be written in a generalized expression: 


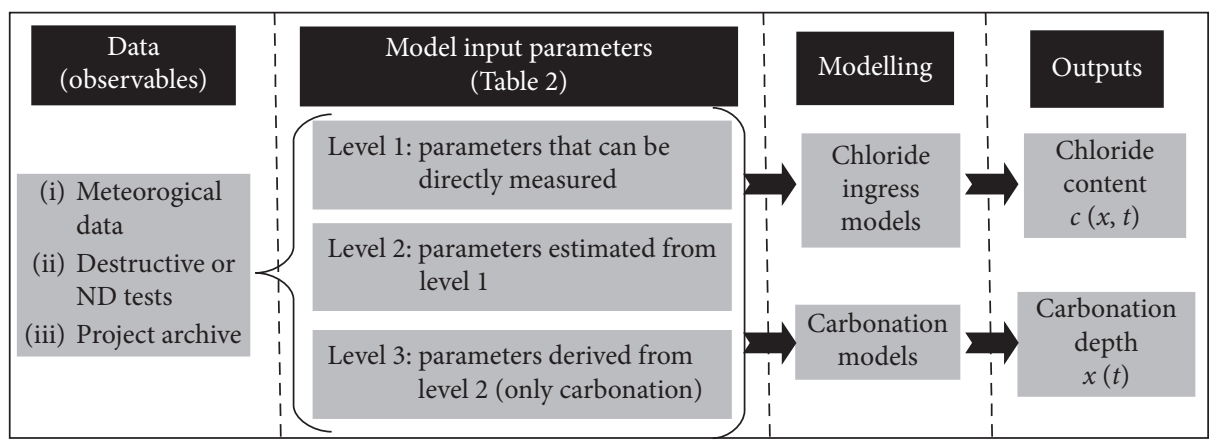

FiguRE 2: General representation of input parameters for analytical carbonation and chloride ingress models by Rakotovao Ravahatra et al. [17].

TABLE 2: Classification and data required for determining model input parameters.

\begin{tabular}{|c|c|c|}
\hline Level & Chloride ingress & Carbonation \\
\hline $1 a^{*}$ & RH (relative humidity), $T$ (temperature) & $\begin{array}{c}\mathrm{RH} \text { (relative humidity), } T \text { (temperature), } P_{\mathrm{CO}_{2}}\left(\mathrm{CO}_{2} \text { pressure), }\right. \\
P_{\mathrm{atm}} \text { (atmospheric pressure) }\end{array}$ \\
\hline $1 b^{* *}$ & $\begin{array}{c}\phi \text { (porosity), } S_{r} \text { (saturation degree), } \rho \text { (concrete density), } \\
\text { migration coefficient, chloride profiles }\end{array}$ & $\begin{array}{c}R_{c} \text { (28 days compressive concrete strength), } \phi \text { (porosity), } S_{r} \\
\text { (saturation degree), } \rho \text { (concrete density) }\end{array}$ \\
\hline $1 c^{* * *}$ & Concrete mix, cement composition, execution conditions & Concrete mix, cement composition, execution conditions \\
\hline 2 & $\begin{array}{c}\text { Diffusion coefficient, } w \text { (water content), } n \text { (aging parameter), } k_{e} \\
\text { (environmental parameter), } k_{c} \text { (execution parameters), } k_{t} \text { (test } \\
\text { method parameter), } C_{s} \text { (surface chloride content) }\end{array}$ & $\begin{array}{l}a \text { (binding capacity for } \mathrm{CO}_{2} \text { ), } a^{\prime} \text { (required quantity of } \mathrm{CO}_{2} \text { for a } \\
\text { complete carbonation), } n \text { (aging parameter), } C_{0} \text { (carbon dioxide } \\
\text { content), } f_{p} \text { (volumetric ratio of cement paste), hydrate content, } \\
\text { unhydrate content, } C_{\text {abs }} \text { (required carbon dioxide content for a } \\
\text { complete hydration of the concrete), } \alpha_{\text {hyd }} \text { (hydration degree), } \alpha_{1} \\
\text { et } n_{1} \text { (fitting parameters of the model of Hyvert), } k_{e} \\
\text { (environmental parameter), } k_{c} \text { (execution parameters), } k_{t} \text { (test } \\
\text { method parameter) }\end{array}$ \\
\hline 3 & & $\begin{array}{l}k_{\text {exp }} \text { (exposure model factor), } k_{\text {exe }} \text { (execution model factor), } k_{P} \\
\text { (factor accounting for the interaction between the diffusion } \\
\text { coefficient and the carbon dioxide), } D_{\mathrm{CO}_{2}} \text { (diffusion coefficient) }\end{array}$ \\
\hline
\end{tabular}

${ }^{*}$ Meteorological data; ${ }^{* *}$ tests or project archives; ${ }^{* * *}$ project archives.

$$
x(t)=\sqrt{k_{\exp } k_{\text {exe }} k_{P} D_{\mathrm{CO}_{2}}} \sqrt{t},
$$

where $x(t)(\mathrm{m})$ is the carbonation depth at time $t(\mathrm{~s}), k_{\text {exp }}$ is a factor which introduces environmental conditions, $k_{\text {exe }}$ is a factor accounting for execution conditions, and $k_{P}$ is a factor accounting for the interaction between the diffusion coefficient of the carbon dioxide $D_{\mathrm{CO}_{2}}\left(\mathrm{~m}^{2} / \mathrm{s}\right)$ and the concrete porosity $\phi$. In some models $[21,25,29], k_{P}$ is expressed as

$$
k_{P}=k_{P, M} k_{P, E},
$$

where $k_{P, M}$ is related to material properties and $k_{P, E}$ to exposure conditions. Expressions of $k_{P, M}, k_{P, E}, k_{\text {exp }}$, and $k_{\text {exe }}$ for each model are detailed in [17]. Table 4 presents the input parameters for each studied carbonation model.

\subsection{Summary of Results of the Sensitivity Analysis}

3.2.1. Methodology. The indicators used in [17] for the sensitivity analysis are (i) elasticity coefficient, (ii) Pearson's coefficient, (iii) bias factor, and (iv) uncertainty propagation (output's standard deviation).

These indicators provide different information concerning the sensitivity of models to their input variation.
Elasticity provides an assessment of the effect of a deterministic disruption of a given input of the model on the output. Pearson's coefficient quantifies the linear correlation between inputs and the output of the model. The bias factor is an assessment of the part of the variability of the model output caused by each input. Finally, the last indicator (uncertainty propagation) quantifies the variability in the model output when a given input varies.

In order to study the effect of the concrete quality, three typical concrete mixes have been accounted for: they are referred as C25, C35, and C45. The compositions of CEM I cement and mixes of these concretes are reported in Tables 5 and 6, respectively. Some physicochemical properties of these concretes are also given in Table 7. Outer surfaces of concrete structures considered in this study are supposed sheltered and exposed to commonly encounter yearly average conditions. Average relative humidity and temperature were thus $72 \%$ and $11^{\circ} \mathrm{C}$, respectively.

The values of input parameters are summarized in $\mathrm{Ta}$ bles 8 and 9 for chloride ingress models and carbonation models, respectively. The range of variability in each parameter corresponds to the possible realistic variability for the three studied concretes. The bounds of each variation interval $\left[a_{i} ; b_{i}\right]$ have been proposed from literature review 


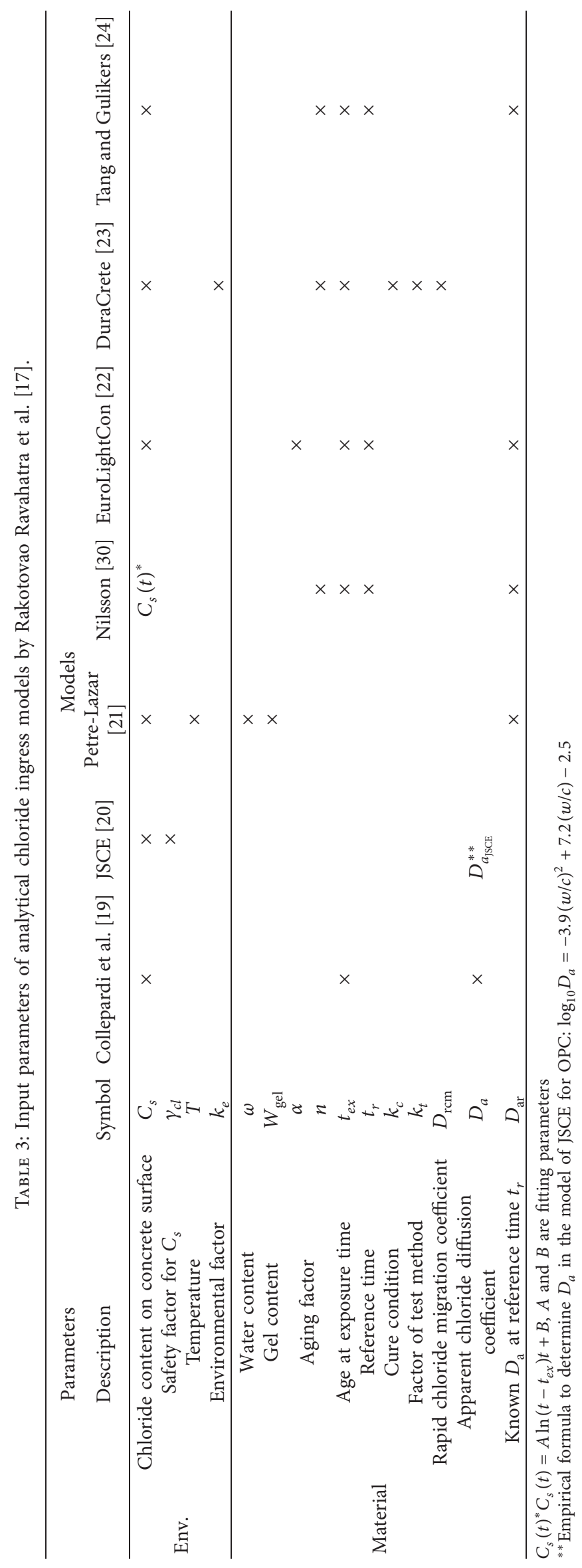


TABLE 4: Input parameters of analytical models of carbonation by Rakotovao Ravahatra et al. [17].

\begin{tabular}{|c|c|c|c|c|c|c|c|c|c|}
\hline & Parameter & & & & Model & & & & \\
\hline & Description & Symbol & $\begin{array}{c}\text { Ying-Yu and } \\
\text { Qui-Dong } \\
{[25]}\end{array}$ & $\begin{array}{l}\text { Papadakis } \\
\text { et al. [26] }\end{array}$ & $\begin{array}{l}\text { CEB } \\
{[27]}\end{array}$ & $\begin{array}{c}\text { DuraCrete } \\
{[23]}\end{array}$ & $\begin{array}{c}\text { Miragliotta } \\
\text { [28] }\end{array}$ & $\begin{array}{c}\text { Petre- } \\
\text { Lazar } \\
{[21]} \\
\end{array}$ & $\begin{array}{c}\text { Hyvert } \\
\text { [29] }\end{array}$ \\
\hline & $\mathrm{CO}_{2}$ pressure & $P_{\mathrm{CO}_{2}}$ & $x$ & & & & & & $x$ \\
\hline & Temperature & $T$ & & & & & & & $x$ \\
\hline Env. & Relative humidity & RH & & $x$ & & & $x$ & $x$ & \\
\hline & $\mathrm{CO}_{2}$ content & $C_{0}$ & & $x$ & $x$ & $x$ & $x$ & & \\
\hline & Porosity & $\phi$ & & & & & $x$ & & \\
\hline & Saturation degree & $S_{r}$ & & & & & $x$ & & \\
\hline & Compressive strength & $R_{c}$ & & & & & & $x$ & \\
\hline & Absorbed $\mathrm{CO}_{2}$ & $C_{\mathrm{abs}}$ & $x$ & & & & & & \\
\hline & Concrete density & $\rho$ & $x$ & & & & & & \\
\hline & Binding capacity for $\mathrm{CO}_{2}$ & $a$ & & & & $x$ & & & \\
\hline & $\begin{array}{l}\text { Required quantity of } \mathrm{CO}_{2} \\
\text { for a complete carbonation }\end{array}$ & $a^{\prime}$ & & & $x$ & & & & \\
\hline Material & CSH content & $\mathrm{CSH}$ & & $x$ & & & $x$ & & $x$ \\
\hline & $\mathrm{CH}$ content & $\mathrm{CH}$ & & $x$ & & & $x$ & & $x$ \\
\hline & AFt content & $\mathrm{AFt}$ & & & & & $x$ & & $x$ \\
\hline & AFm content & AFm & & & & & $x$ & & $x$ \\
\hline & $\mathrm{C}_{3} \mathrm{~S}$ content & $\mathrm{C}_{3} \mathrm{~S}$ & & $x$ & & & $x$ & & \\
\hline & $\mathrm{C}_{2} \mathrm{~S}$ content & $\mathrm{C}_{2} \mathrm{~S}$ & & $x$ & & & $x$ & & \\
\hline & $\mathrm{C}_{3} \mathrm{~A}$ content & $\mathrm{C}_{3} \mathrm{~A}$ & & & & & $x$ & & \\
\hline & $\mathrm{C}_{4} \mathrm{AF}$ content & $\mathrm{C}_{4} \mathrm{AF}$ & & $x$ & & & $x$ & & \\
\hline & Reference period & $t_{0}$ & & & $x$ & $x$ & & & \\
\hline & Fitting parameters & $\begin{array}{c}\alpha_{1} \text { and } \\
n_{1}\end{array}$ & & & & & & & $x$ \\
\hline
\end{tabular}

TABLE 5: Cement composition (\%).

\begin{tabular}{lccccccc}
\hline Concrete & $\mathrm{SiO}_{2}$ & $\mathrm{Al}_{2} \mathrm{O}_{3}$ & $\mathrm{Fe}_{2} \mathrm{O}_{3}$ & $\mathrm{CaO}$ & $\mathrm{MgO}$ & $\mathrm{KO}_{3} \mathrm{O}$ \\
\hline $\mathrm{C} 45$ & 20.1 & 5 & 3 & 64.1 & 1 & 3.2 & 0.72 \\
$\mathrm{C} 35$ & 20.43 & 4.9 & 1.83 & 65.4 & 1.06 & 3.5 \\
$\mathrm{C} 25$ & 20.29 & 5.56 & 2.32 & 64.22 & 2 & 0.25 \\
\hline
\end{tabular}

TABLe 6: Concrete mixes $\left(\mathrm{kg} / \mathrm{m}^{3}\right)$.

\begin{tabular}{lcccccccc}
\hline Concrete & Cement & Fly ash & Sand 0/4 & Aggregates 4/12 & Aggregates 12/20 & Water & Superplasticizer & $w / c$ \\
\hline C45 & 350 & 80 & 900 & 320 & 630 & 177 & 3 \\
C35 & 350 & 0 & 815 & 998 & 0 & 195 & 1.4 \\
C25 & 295 & 0 & 989 & 792 & 0 & 200 & 0.51 \\
\hline
\end{tabular}

TABle 7: Physicochemical properties (mol/L).

\begin{tabular}{lccccccc}
\hline Concrete & $\mathrm{AFm}$ & $\mathrm{AFt}$ & $\mathrm{CSH}$ & $\mathrm{CH}$ & $\mathrm{SiO}_{2}$ & Porosity $(\%)$ & 11.8 \\
\hline $\mathrm{C} 45$ & 0.41 & 0.25 & 3.16 & 3.11 & 0 & $R_{c}(\mathrm{MPa})$ \\
$\mathrm{C} 35$ & 0.41 & 0.15 & 3.185 & 3.585 & 0 & 12.7 & 58 \\
$\mathrm{C} 25$ & 0.34 & 0.25 & 2.879 & 2.90 & 0 & 46.2 \\
\hline
\end{tabular}

$[23,31,32]$ or experimental data. Uniform distributions were used for generating random values.

Although cement paste hydrate and unhydrate contents are input parameters for some models, it was decided to consider their variability through hydration degree $\alpha_{\text {hyd }}$ and cement content $c$, using the empirical expressions, found in [29].
3.2.2. Chloride Ingress Models. For illustration purposes, we present in Table 10 results for all indicators for Collepardi and Luping models. These models were selected because they represent cases with constant (group 1) and time-dependent (group 2) parameters, respectively. All results for the other models are detailed in [17].

The main tendencies are summarized as follows: 
TABLE 8: Values of input parameters for chloride ingress models by Rakotovao Ravahatra et al. [17].

\begin{tabular}{|c|c|c|c|c|c|}
\hline Parameters & Units & Mean & Coef. of variation & Min $a_{i}$ & $\operatorname{Max} b_{i}$ \\
\hline$C_{s}-\mathrm{C} 45$ & & 6.24 & - & 5.29 & 7.19 \\
\hline$C_{s}-\mathrm{C} 35$ & $\%$ mass of binder & 8.76 & - & 8.37 & 9.17 \\
\hline$C_{s}-\mathrm{C} 25$ & & 10.01 & - & 9.52 & 10.49 \\
\hline$T$ & Kelvin & 284.04 & 0.067 & 282.55 & 285.53 \\
\hline$D_{a}-\mathrm{C} 45$ & & 2.99 & 0.136 & 1.95 & 2,57 \\
\hline$D_{a}-\mathrm{C} 35$ & $10^{-12} \mathrm{~m}^{2} / \mathrm{s}$ & 3.45 & 0.136 & 2.99 & 3.92 \\
\hline$D_{a}-\mathrm{C} 25$ & & 7.09 & 0.133 & 6.15 & 8,04 \\
\hline$W_{\mathrm{gel}}-\mathrm{C} 45$ & & 205.19 & - & 198.62 & 211.76 \\
\hline$W_{\mathrm{gel}^{2}}^{\mathrm{g}-\mathrm{C} 35}$ & $\mathrm{~kg} / \mathrm{m}^{3}$ & 208.56 & - & 201.88 & 215.23 \\
\hline$W_{\mathrm{gel}}^{\mathrm{g}-\mathrm{C} 25}$ & & 174.58 & - & 168.99 & 180.17 \\
\hline$w-\mathrm{C} 45$ & & 118 & 0.05 & 112.1 & 123.9 \\
\hline$w-\mathrm{C} 35$ & $\mathrm{~kg} / \mathrm{m}^{3}$ & 127 & 0.012 & 125.47 & 128.52 \\
\hline$w-\mathrm{C} 25$ & & 140 & 0.06 & 131.6 & 148.4 \\
\hline$k_{c}$ & & 0.656 & 0.26 & 0.48 & 0.82 \\
\hline$k_{t}$ & & 0.832 & 0.029 & 0.80 & 0.85 \\
\hline$k_{e}-\mathrm{C} 45, \mathrm{C} 35$ & & 1.325 & 0.17 & 1.09 & 1.55 \\
\hline$k_{e}-\mathrm{C} 25$ & & 0.676 & 0.18 & 0.55 & 0.79 \\
\hline$n-\mathrm{C} 45$ & & 0.69 & 0,07 & 0.6417 & 0.7383 \\
\hline$n$-C35, C25 & & 0.3 & 0.17 & 0.249 & 0.351 \\
\hline$\alpha-\mathrm{C} 45, \mathrm{C} 35$ & & 0.60 & 0,07 & 0.558 & 0.642 \\
\hline$\alpha-\mathrm{C} 25$ & & 0.40 & 0.17 & 0.332 & 0.468 \\
\hline$D_{\mathrm{rcm}}-\mathrm{C} 45$ & & 4.14 & 0.136 & 3.57 & 4,70 \\
\hline$D_{\mathrm{rcm}}-\mathrm{C} 35$ & $10^{-12} \mathrm{~m}^{2} / \mathrm{s}$ & 6.33 & 0.136 & 5.47 & 7,19 \\
\hline$D_{\mathrm{rcm}}-\mathrm{C} 25$ & & 13 & 0.133 & 11.27 & 14.73 \\
\hline$\gamma_{c l}$ & & - & - & 1.00 & 1.30 \\
\hline$w / c-C 45$ & & 0.51 & 0.027 & 0.50 & 0.52 \\
\hline$w / c-\mathrm{C} 35$ & & 0.56 & 0.027 & 0.54 & 0.57 \\
\hline$w / c-\mathrm{C} 25$ & & 0.68 & 0.027 & 0.66 & 0.70 \\
\hline
\end{tabular}

- , no data.

TABle 9: Values of input parameters for carbonation models by Rakotovao Ravahatra et al. [17].

\begin{tabular}{|c|c|c|c|c|c|}
\hline Parameter & Unit & Mean & Coef. of variation (\%) & $\operatorname{Min} a_{i}$ & $\operatorname{Max} b_{i}$ \\
\hline RH & $\%$ & 72.91 & 3 & 70.68 & 75.14 \\
\hline$R_{c}-\mathrm{C} 45$ & & 58 & 6 & 54.52 & 61.48 \\
\hline$R_{c}-\mathrm{C} 35$ & $\mathrm{MPa}$ & 46.2 & 4 & 44.35 & 48.04 \\
\hline$R_{c}-\mathrm{C} 25$ & & 40.2 & 3 & 38.99 & 41.40 \\
\hline$k_{c}$ & - & 0.63 & 26 & 0.46 & 0.79 \\
\hline$k_{t}$ & - & 0.98 & 2.3 & 0.96 & 1.005 \\
\hline$n$ & - & 0.4 & 20 & 0.32 & 0.48 \\
\hline$R_{\mathrm{carb}}-\mathrm{C} 45$ & $10^{10} \mathrm{~kg} \mathrm{CO}_{2} / \mathrm{m}^{3} /\left(\mathrm{m}^{2} / \mathrm{s}\right)$ & 2 & 7.5 & 1.9 & 2.1 \\
\hline$R_{\mathrm{carb}}-\mathrm{C} 35$ & & 0.4 & 8.9 & 0.36 & 0.43 \\
\hline$R_{\mathrm{carb}}-\mathrm{C} 25$ & & 0.28 & 5 & 0.271 & 0.3 \\
\hline$T$ & $K$ & 284.04 & 6.7 & 282.55 & 285.53 \\
\hline$\phi-\mathrm{C} 45$ & & 0.118 & 5 & 0.112 & 0.124 \\
\hline$\phi-\mathrm{C} 35$ & - & 0.127 & 1.6 & 0.124 & 0.129 \\
\hline$\phi-\mathrm{C} 25$ & & 0.14 & 8 & 0.129 & 0.151 \\
\hline$c-\mathrm{C} 45$ & & 350 & 14 & 345 & 355 \\
\hline$c-\mathrm{C} 35$ & $\mathrm{~kg} / \mathrm{m}^{3}$ & 350 & 13.6 & 345 & 355 \\
\hline$c-\mathrm{C} 25$ & & 295 & 16 & 290 & 300 \\
\hline$\alpha_{\text {hyd }}-\mathrm{C} 45$ & & 0.81 & 3.9 & 0.778 & 0.842 \\
\hline$\alpha_{\text {hyd }}-\mathrm{C} 35$ & - & 0.84 & 3.8 & 0.808 & 0.872 \\
\hline$\alpha_{\text {hyd }}-\mathrm{C} 25$ & & 0.89 & 3.6 & 0.858 & 0.922 \\
\hline$\overline{S_{r}}$ & - & 0.65 & 10 & 0.59 & 0.72 \\
\hline
\end{tabular}


TABLE 10: Results of sensitivity analysis for two models of chlorination (Collepardi (Col.) and Luping) at $2.5 \mathrm{~cm}$ [17].

\begin{tabular}{|c|c|c|c|c|c|c|c|c|c|c|c|c|}
\hline \multirow{2}{*}{ Indicator } & \multirow{2}{*}{ Model } & \multirow{2}{*}{\multicolumn{2}{|c|}{$\begin{array}{c}\text { Concrete } \\
\text { Age (years) }\end{array}$}} & \multicolumn{3}{|c|}{$\mathrm{C} 45$} & \multicolumn{3}{|c|}{ C35 } & \multicolumn{3}{|c|}{$\mathrm{C} 25$} \\
\hline & & & & 10 & 25 & 50 & 10 & 25 & 50 & 10 & 25 & 50 \\
\hline \multirow{5}{*}{ Elasticity } & \multirow{2}{*}{ Col. } & Env. & $C_{s}$ & 1 & 1 & 1 & 1 & 1 & 1 & 1 & 1 & 1 \\
\hline & & Mat. & $D_{\mathrm{a}}$ & 3.1 & 1.31 & 0.74 & 0.52 & 0.27 & 0.17 & 0.31 & 0.17 & 0.11 \\
\hline & \multirow{3}{*}{ Luping } & Env. & $C_{s}^{a}$ & 1 & 1 & 1 & 1 & 1 & 1 & 1 & 1 & 1 \\
\hline & & Mat & $D_{\text {ar }}$ & 1.6 & 1.24 & 1.04 & 0.47 & 0.3 & 0.21 & 0.28 & 0.18 & 0.13 \\
\hline & & Mat. & $n$ & -1.32 & -1.82 & -2.04 & -0.51 & -0.42 & -0.36 & -0.31 & -0.26 & -0.23 \\
\hline \multirow{5}{*}{ Pearson's coef. } & \multirow{2}{*}{ Col. } & Env. & $C_{s}$ & 0.35 & 0.63 & 0.81 & 0.98 & 0.99 & 0.99 & 0.71 & 0.87 & 0.94 \\
\hline & & Mat. & $D_{\mathrm{a}}$ & 0.93 & 0.78 & 0.59 & 0.16 & 0.08 & 0.05 & 0.69 & 0.46 & 0.32 \\
\hline & \multirow{3}{*}{ Luping } & Env. & $C_{s}^{a}$ & 0.5 & 0.53 & 0.55 & 0.38 & 0.47 & 0.55 & 0.58 & 0.67 & 0.74 \\
\hline & & Mat & $D_{\mathrm{ar}}$ & 0.74 & 0.62 & 0.54 & 0.58 & 0.47 & 0.4 & 0.49 & 0.38 & 0.3 \\
\hline & & Mat. & $n$ & -0.41 & -0.55 & -0.61 & -0.72 & -0.74 & -0.73 & -0.62 & -0.61 & -0.58 \\
\hline \multirow{5}{*}{ Bias factor } & \multirow{2}{*}{ Col. } & Env. & $C_{s}$ & 0.43 & 1.48 & 2.06 & -0.31 & -0.32 & -0.34 & 0.22 & 0.48 & 0.63 \\
\hline & & Mat. & $D_{\mathrm{a}}$ & 15.59 & -18.17 & -47.09 & -0.94 & -0.94 & -0.94 & -84.68 & -63.28 & -47.25 \\
\hline & \multirow{3}{*}{ Luping } & Env. & $C_{s}^{\mathrm{a}}$ & 45.95 & 45.91 & 40.6 & -4.41 & -7.53 & -10.39 & -96.74 & -100.66 & -99.12 \\
\hline & & Mat & $D_{\mathrm{ar}}$ & 54.18 & 69.64 & 75.25 & -82.08 & -85.2 & -87.9 & -15.11 & -34.59 & -44.97 \\
\hline & & Mat. & $n$ & -7.6 & -22.41 & -32.6 & -4.23 & -7.32 & -10.15 & -81.25 & -65.77 & -54.07 \\
\hline \multirow{5}{*}{ Output's std. } & \multirow{2}{*}{ Col. } & Env. & $C_{s}$ & 0.01 & 0.08 & 0.17 & 0.09 & 0.14 & 0.16 & 0.16 & 0.2 & 0.22 \\
\hline & & Mat. & $D_{\mathrm{a}}$ & 0.03 & 0.1 & 0.12 & 0.01 & 0.01 & 0 & 0.15 & 0.1 & 0.07 \\
\hline & \multirow{3}{*}{ Luping } & Env. & $C_{s}^{a}$ & 0.05 & 0.08 & 0.11 & 0.1 & 0.13 & 0.15 & 0.16 & 0.19 & 0.21 \\
\hline & & \multirow{2}{*}{ Mat. } & $D_{\mathrm{ar}}^{\mathrm{s}}$ & 0.08 & 0.1 & 0.11 & 0.16 & 0.13 & 0.11 & 0.14 & 0.11 & 0.09 \\
\hline & & & $n$ & 0.05 & 0.09 & 0.12 & 0.2 & 0.21 & 0.2 & 0.18 & 0.18 & 0.17 \\
\hline
\end{tabular}

Env., environmental parameter; Mat., material parameter.

(i) Differences were observed between the two groups regarding sensitivity analysis: the models belonging to the second group are more sensitive to material parameters.

(ii) It was found for both groups of models that, at early age, material parameters are the most influential $\left(D_{\mathrm{a}}\right.$ for the Collepardi model and $D_{\text {ar }}$ and $n$ for Luping model).

(iii) At advanced age, environmental parameters become more influential $\left(C_{s}\right.$ for Collepardi and Luping models).

3.2.3. Concrete Carbonation Models. Table 11 gives the results of the sensitivity analysis for all carbonation models. For each model, the maximum and minimum values of each indicator are highlighted with bold text. The main tendencies are summarized as follows:

(i) The impact on the mean and standard deviation of the output varies over time, but the results of elasticity and the linear Pearson's correlation coefficient remain fairly constant.

(ii) The results show that the most influencing parameters are those which are linked to the concrete porosity and its condition state: these are the relative humidity $\mathrm{RH}$, the curing factor $k_{c}$, and the porosity $\phi$.

\section{Categories of Structures and Materials}

Two typical study cases for existing constructions with respect to their available data are investigated in this work: (i) structure A with a complete building archive, with exhaustive information, and (ii) structure B with a slight building archive and quite poor information. These structures were chosen within the framework of the ANREVADEOS project (http://www.agence-nationalerecherche.fr/Projet-ANR-11-VILD-0002). The 2 building archives of the considered structures are presented in Table 12 .

For each case (structures A and B), the three concrete types previously considered in the sensitivity analysis are considered again.

\section{Assessment of Costs}

5.1. Input Parameters Costs. When supplying input parameters for a predictive model, the engineer may adopt two possible approaches that can be combined eventually. The expert advice approach consists in gathering all available information, deal with them for using the model if these information are more or less direct input parameters. He can also complete them by additional computations or engineering knowledge if these information can be introduced as input parameters of intermediate models whose outputs would be used as input parameters of the predictive model. The auscultation data approach consists in extracting material properties or other information from destructive or (preferably) nondestructive tests that can be used as more or less direct input parameters of the predictive model. Both approaches present several complexity levels depending on the number of steps to operate for supplying a particular input parameter. Each input parameter of a predictive model can be therefore associated with a certain complexity level (Table 13) and consequently to a certain cost which can be different according to the adopted approach. Table 14 reported the values of the cost $(\mathrm{C})$, accuracy level (A), and the 
TABLE 11: Summary of the results of sensitivity analysis for all concrete carbonation models at 50 years [17].

\begin{tabular}{|c|c|c|c|c|c|c|c|c|c|c|c|c|c|}
\hline \multicolumn{2}{|c|}{ Concrete } & \multicolumn{4}{|c|}{$\mathrm{C} 45$} & \multicolumn{4}{|c|}{ C35 } & \multicolumn{4}{|c|}{$\mathrm{C} 25$} \\
\hline Models & Parameter & $E$ & $P$ & $M$ & Std. & $E$ & $P$ & $M$ & Std. & $E$ & $P$ & $M$ & Std. \\
\hline \multirow{5}{*}{ DuraCrete } & $R_{\text {carb }}$ & -0.46 & -0.1 & 1229.2 & 3.28 & -0.46 & -0.08 & 8541.26 & 3.04 & -0.46 & -0.04 & 1170.37 & 2.3 \\
\hline & $\mathrm{RH}$ & -1.93 & -0.13 & 1229.99 & 4.33 & -1.93 & 0.03 & 8525.41 & 1.04 & -1.93 & -0.1 & 1172.11 & 4.6 \\
\hline & $k_{c}$ & 0.48 & 0.37 & 1250 & 11.42 & 0.48 & 0.24 & 8644.25 & 8.92 & 0.48 & 0.23 & 1184.31 & 12.2 \\
\hline & $k_{t}$ & 0.48 & 0.05 & 1227.9 & 1 & 0.48 & 0.02 & 8523.79 & 0.78 & 0.48 & 0.01 & 1169.65 & 1.05 \\
\hline & $n$ & -1.44 & -0.89 & 1404.14 & 27.66 & -1.48 & -0.95 & 11376.55 & 36.61 & -1.48 & -0.95 & 1557.57 & 50.4 \\
\hline \multirow{4}{*}{ CEB } & $R_{\text {carb }}$ & -0.46 & -0.04 & 0.47 & 2.08 & -0.46 & -0.67 & 216.64 & 5.79 & -0.46 & -0.04 & 0.49 & 0.23 \\
\hline & $\mathrm{RH}$ & -1.93 & -0.08 & -1.58 & 4.14 & -1.93 & -0.06 & -1.25 & 0.35 & -1.93 & -0.09 & -1.57 & 0.46 \\
\hline & $k_{c}$ & 0.48 & 0.24 & -4.01 & 10.9 & 0.48 & 0.14 & -4.51 & 0.92 & 0.48 & 0.24 & -5.07 & 1.23 \\
\hline & $n$ & -2.28 & -0.95 & 65.32 & 44.81 & -2.28 & -0.55 & 61.84 & 3.78 & -2.28 & -0.95 & 73.51 & 5.07 \\
\hline \multirow{2}{*}{ Oxand } & $\mathrm{RH}$ & -1.3 & 0.06 & -5.34 & 7.56 & -1.76 & -0.92 & 10204.19 & 21.03 & -1.76 & -0.96 & -618.89 & 31.6 \\
\hline & $R_{c}$ & -13.38 & -0.99 & 41.08 & 123.47 & -3.24 & -0.36 & 9779.7 & 8.2 & -2.31 & -0.2 & 9.41 & 6.59 \\
\hline \multirow{6}{*}{ Ying-Yu } & RH & -2.92 & -0.68 & 0.08 & 0.35 & -2.92 & -0.64 & 9 & 0.35 & -2.92 & -0.69 & 0.11 & 0.48 \\
\hline & $\alpha_{\text {hyd }}$ & -0.53 & -0.15 & -0.01 & 0.08 & -0.53 & -0.13 & -2 & 0.08 & -0.23 & -0.09 & 0.01 & 0.5 \\
\hline & $S_{r}$ & 1.09 & 0.71 & 0.29 & 0.36 & 1.09 & 0.66 & 0.03 & 0.37 & 1.09 & 0.71 & 0.04 & 0.5 \\
\hline & $\phi$ & 0.89 & -0.16 & -0.96 & 0.18 & 0.89 & -0.38 & -0.003 & 0.06 & 0.6 & -0.17 & -1.58 & 0.26 \\
\hline & $c$ & -0.77 & -0.09 & 0.01 & 0.05 & -0.75 & -0.08 & 0.02 & 0.05 & -0.41 & -0.06 & 0.0002 & 0.05 \\
\hline & $\rho$ & -0.91 & -0.16 & 0.36 & 0.27 & -0.91 & -0.38 & 0.85 & 0.28 & -0.91 & -0.17 & 0.45 & 0.37 \\
\hline \multirow{5}{*}{ Miragliotta } & RH & -2.91 & -0.53 & 0.03 & 3.58 & -2.91 & -0.66 & 0.07 & 3.7 & -2.91 & -0.47 & 0.16 & 6.8 \\
\hline & $\alpha_{\text {hyd }}$ & -0.11 & 0.001 & 0.0003 & 0.17 & -0.13 & -0.04 & 0.004 & 0.2 & 0.24 & 0.05 & 0.12 & 0.6 \\
\hline & $S_{r}$ & -0.97 & -0.57 & -0.98 & 5.4 & -0.97 & -0.68 & -1.02 & 4.01 & -0.97 & -0.49 & -1.83 & 12.5 \\
\hline & $\phi$ & 2.05 & 0.59 & 0.3 & 3.94 & 2.05 & 0.24 & 0.04 & 1.3 & 1.75 & 0.71 & 1.39 & 10.3 \\
\hline & $c$ & -1.19 & -0.11 & 0.05 & 0.72 & -1.17 & -0.14 & 0.04 & 0.7 & -0.85 & -0.08 & 0.1 & 1.3 \\
\hline \multirow{4}{*}{ Papadakis } & RH & -2.91 & -0.78 & 0.41 & 16.68 & -2.91 & -0.95 & 0.21 & 16.5 & -2.91 & -0.67 & 0.43 & 24.8 \\
\hline & $\alpha_{\text {hyd }}$ & -0.11 & -0.04 & -0.01 & 0.87 & -0.14 & -0.07 & 0.01 & 0.9 & 0.21 & 0.04 & 0.37 & 1.9 \\
\hline & $c$ & -1.16 & -0.13 & 0.16 & 3.3 & -1.17 & -0.18 & 0.2 & 3.2 & -0.94 & -0.1 & 0.23 & 4.7 \\
\hline & $\phi$ & 1.38 & 0.6 & -0.31 & 12.88 & 1.41 & 0.23 & -0.05 & 4.1 & 1.19 & 0.71 & -1.21 & 26.3 \\
\hline \multirow{6}{*}{ Hyvert } & $\mathrm{RH}$ & -4.29 & -0.69 & 2.44 & 31.59 & -4.29 & -0.72 & 0.06 & 0.07 & -4.29 & -0.63 & 3.8 & 4.69 \\
\hline & $T$ & -0.46 & -0.1 & 0.01 & 0.59 & -0.46 & -0.04 & 0.0003 & 0.001 & -0.46 & -0.003 & 0.0028 & 0.012 \\
\hline & $k_{c}$ & 0.48 & 0.65 & -11.15 & 29.52 & 0.48 & 0.67 & -0.27 & 0.07 & 0.48 & 0.65 & 15.01 & 4.18 \\
\hline & $\phi$ & 0.67 & 0.16 & -1.26 & 8.03 & 0.002 & -0.01 & $-10^{-5}$ & $6 \times 10^{-5}$ & 0.49 & 0.22 & -3.5 & 1.5 \\
\hline & $c$ & -1.29 & -0.1 & 0.32 & 4.59 & -0.65 & -0.04 & 0.003 & 0.005 & -1.13 & -0.13 & -0.7 & 0.71 \\
\hline & $\alpha_{\text {hyd }}$ & -1.19 & -0.21 & 1.63 & 9.48 & -0.55 & 0.004 & $-7 \times 10^{-7}$ & $2 \times 10^{-5}$ & -1.05 & -0.15 & -2.5 & 1.25 \\
\hline
\end{tabular}

$E=$ elasticity coefficient; $P=$ Pearson's coefficient; $M=$ bias on the output's mean $\left(\times 10^{-6} \mathrm{~m}\right)$; Std. $=$ output's standard deviation $\left(\times 10^{-4} \mathrm{~m}\right)$.

TABLE 12: Building archives of the 2 considered structures A and B.

\begin{tabular}{lcc}
\hline Data & Complete building archive (A) & Slight building archive (B) \\
\hline Structure & & Given \\
Date of construction & Given & Available \\
Architectural plan & Available & Available \\
Reinforcement plan & Available & Missing \\
Design calculations and report & Available & Given \\
\hline Concrete & & Missing \\
Concrete type (regular concrete, high performance, etc.) & Given & Missing \\
Aggregate contents & Given & Missing \\
Cement content & Given & Missing \\
$w / c$ & Given & Given \\
Cure duration $\left(k_{c}\right)$ & Given & Missing \\
$R_{c}$ & Given within compliance test report & Missing \\
\hline Cement & & Given \\
Type & Detailed (technical datasheet) & \\
Composition & & \\
\hline
\end{tabular}

level of robustness loss risk (RLR) for each complexity level (CL). It is important to notice that the costs mentioned in this study are not real financial costs but rather represent an intellectual cost of operational investment. This encompasses the time spent to obtain and analyze a result and the required expertise. It could be seen as scale of increase in the 
TABLE 13: Level of complexity with respect to the situation of supplying model's parameters.

\begin{tabular}{|c|c|c|}
\hline \multirow{2}{*}{$\begin{array}{l}\text { Complexity } \\
\text { level }\end{array}$} & \multicolumn{2}{|c|}{ Supplied from } \\
\hline & Expert advice & Auscultation data \\
\hline 1 & Available in the building archive & Available data (e.g., meteorological data) \\
\hline 2 & $\begin{array}{l}\text { Not directly available in the building archive, may be } \\
\text { assessed by empirical relationships using data of level 1, or } \\
\text { with an average level of expert knowledge }\end{array}$ & $\begin{array}{l}\text { Destructive or NDT (may require extraction process with } \\
\text { limited experimental testing and direct assessment with } \\
\text { NDT) }\end{array}$ \\
\hline 3 & $\begin{array}{l}\text { Not available in the building archive, requires literature } \\
\text { investigation, could be assessed with intermediate models } \\
\text { using data from level 2, requires good expert knowledge }\end{array}$ & $\begin{array}{c}\text { Destructive or NDT (may require extraction process with } \\
\text { specific experimental testing and requires indirect } \\
\text { assessment from NDT data analysis) }\end{array}$ \\
\hline 4 & $\begin{array}{l}\text { Could only be computed with advanced intermediate } \\
\text { models, could be assessed with a high level of expert } \\
\text { knowledge }\end{array}$ & $\begin{array}{c}\text { Only destructive testing, with particular experimental } \\
\text { procedure, or may require combination of several } \\
\text { experimental tests }\end{array}$ \\
\hline
\end{tabular}

TABLE 14: Correspondence between complexity level (CL), cost (C), accuracy level (A), and level of robustness loss risk (RLR) for input parameters.

\begin{tabular}{|c|c|c|c|c|c|c|}
\hline \multirow{3}{*}{ Complexity level (CL) } & \multicolumn{6}{|c|}{ Supplied from } \\
\hline & \multicolumn{3}{|c|}{ Expert advice } & \multicolumn{3}{|c|}{ Auscultation data } \\
\hline & $\mathrm{C}$ & A & RLR & $\mathrm{C}$ & $\mathrm{A}$ & RLR \\
\hline 1 & 1 & 1 & 1 & 2 & 4 & 1 \\
\hline 2 & 2 & 2 & 2 & 4 & 6 & 2 \\
\hline 3 & 4 & 3 & 3 & 8 & 8 & 3 \\
\hline 4 & 8 & 4 & 4 & 16 & 10 & 4 \\
\hline
\end{tabular}

cost when complexity increases. In Table 14, we found that when the method used is two times more complex, the cost is two times higher. Thus, defining scale of intellectual cost is quite difficult. This study is an attempt for such an approach. The concept of value of information (VoI) by Kuhn [12] could be cited as a similar approach; however, no definition of parameter cost is proposed within that theory. Besides, it is assumed that costs are higher in the auscultation data approach than in the expert advice approach, for a same complexity level. Indeed, auscultations may involve complex equipment which requires additional skills and time. Complex experimental procedures also require high level of expertise. On the contrary, it is necessary to characterize not only the accuracy level but also the robustness of the method used for the supplying. The robustness of a given system is its capacity to remain unaffected by small variations in the system itself and its environment [33-35]. Since uncertainties are taken into account in the proposed methodology, it is necessary to estimate the RLR, especially when CL increases because experimental or computation inaccuracies are expected to accumulate as function of CL. The value of RLR is the same for expert advice or auscultation.

On the contrary, as mentioned in Section 2, in some practical cases, degradation models are directly used to identify inputs from measured outputs. When identifications are carried out, some compensation could appear between the identified parameters, especially when the model used has too many parameters. These cases correspond to level of complexities 3 and 4 from expert advice in Table 13. When we identify parameters within realistic imposed ranges of values, the compensation is limited although still existing. Such identification process is not involved in the current study. In the proposed methodology, we suppose that the residual compensation, if it exists, could be included into the RLR.

Accuracy (A) reflects the magnitude of the uncertainties on estimation. First, A increases for larger complexity levels (CL). Second, when a given parameter is supplied using an expert advice method, even the most complex one $(\mathrm{CL}=4)$, the accuracy (A) of this subjective evaluation is always lower than when it is obtained from auscultation (even for the simplest auscultation method $(\mathrm{CL}=1))$. This illustrates the fact that it is always suitable to get direct on site information rather than information provided by a complex expert advice requiring possible additional assumptions. This approach allows us to efficiently rank the models appearing equivalent from a prediction point of view.

Let us now focus on the evolution of the values in $\mathrm{Ta}$ ble 14 for various complexity levels. Note that a geometrical series is selected for $\mathrm{C}$, whereas arithmetical series are selected for A and RLR. Indeed, economically, cost increases geometrically when demand increases arithmetically [36]. We observe A cost of 1 is attributed when data are directly available from archive. For the other complexity level (CL), $\mathrm{C}$ increases due to the cost of more complex on-site investigation. For example, this increase in costs can be observed when analyzing some technical auscultation guidelines, such as those by Thauvin and Rouxel [37].

5.1.1. Case of Chloride Ingress Models. Table 15 reports complexity levels (CL), corresponding costs (C), accuracy 
TABLE 15: Complexity level (CL), cost (C), accuracy level (A), and the level of robustness loss risk (RLR) with respect to structures A and B and for the input parameters of chloride ingress models.

\begin{tabular}{|c|c|c|c|c|c|c|c|c|c|c|c|c|c|c|c|c|}
\hline & \multicolumn{8}{|c|}{ Structure A } & \multicolumn{8}{|c|}{ Structure B } \\
\hline & \multicolumn{4}{|c|}{ Expert advice } & \multicolumn{4}{|c|}{ Auscultation data } & \multicolumn{4}{|c|}{ Expert advice } & \multicolumn{4}{|c|}{ Auscultation data } \\
\hline & $\mathrm{CL}$ & $\mathrm{C}$ & A & RLR & $\mathrm{CL}$ & $\mathrm{C}$ & A & RLR & $\mathrm{CL}$ & $\mathrm{C}$ & A & RLR & $\mathrm{CL}$ & $\mathrm{C}$ & $\mathrm{A}$ & RLR \\
\hline$w / c$ & 1 & 1 & 1 & 1 & 4 & 16 & 10 & 4 & - & - & - & - & 4 & 16 & 10 & 4 \\
\hline$D_{\mathrm{rcm}}$ & 2 & 2 & 2 & 2 & 4 & 16 & 10 & 4 & - & - & - & - & 4 & 16 & 10 & 4 \\
\hline$k_{e}$ & 2 & 2 & 2 & 2 & - & 一 & - & - & - & - & 一 & - & - & - & - & - \\
\hline$k_{c}$ & 2 & 2 & 2 & 2 & - & - & - & - & - & - & - & - & - & - & - & - \\
\hline$k_{t}$ & 2 & 2 & 2 & 2 & - & - & - & - & - & - & - & - & - & - & - & - \\
\hline$n$ & 2 & 2 & 2 & 2 & - & - & - & - & - & - & - & - & - & - & - & - \\
\hline$\alpha$ & 2 & 2 & 2 & 2 & - & - & - & - & - & - & - & - & - & - & - & - \\
\hline$C_{s}$ & 2 & 2 & 2 & 2 & 4 & 16 & 10 & 4 & - & - & - & - & 4 & 16 & 10 & 4 \\
\hline$D_{\mathrm{a}}$ or $D_{\mathrm{ar}}$ & 3 & 4 & 3 & 3 & 4 & 16 & 10 & 4 & - & - & - & - & 4 & 16 & 10 & 4 \\
\hline$W_{\text {gel }}$ & 3 & 4 & 3 & 3 & 4 & 16 & 10 & 4 & - & - & - & - & 4 & 16 & 10 & 4 \\
\hline$T^{8}$ & 1 & 1 & 1 & 1 & 1 & 2 & 4 & 1 & 1 & 1 & 1 & 1 & 1 & 2 & 4 & 1 \\
\hline$w$ & 3 & 4 & 3 & 3 & 2 & 4 & 6 & 2 & - & - & - & - & 2 & 4 & 6 & 2 \\
\hline$\gamma_{c l}$ & 3 & 4 & 3 & 3 & - & - & - & - & 3 & 4 & 3 & 3 & - & - & - & - \\
\hline
\end{tabular}

- , cannot be supplied.

levels (A), and levels of robustness loss risk (RLR), with respect to structures $A$ and $B$, for the input parameters of chloride ingress models (see the nomenclature).

The water to cement ratio $w / c$ is available in a complete building archive (structure A), and then, its supplying corresponds to the lowest complexity level (equal to 1). The corresponding cost, accuracy level, and level of robustness loss risk are all equal to 1 when supplied through expert advice. Regarding structure B (slight building archive), this parameter cannot be supplied through expert advice. The auscultation of this parameter in a hardened concrete and hence in a real structure is quite difficult. An experimental method is proposed in [31]. Therefore, the complexity level for supplying this parameter through auscultation is equal to 4.

Some parameters cited in Table 2 are not directly available in building archive $\left(C_{s}, D_{\mathrm{rcm}}, k_{c}, k_{e}, k_{t}, n\right.$, and $\left.\alpha\right)$. However, when binder and concrete types are available (case of complete building archive), the corresponding values of these parameters can be supplied using the DuraCrete report [23] and EuroLight report [22] for $\alpha$. This corresponds to a complexity level equal to 2 for expert advice. When slight building archive is available (structure B), these parameters cannot be supplied through expert advice. Regarding auscultation, $C_{s}$ can be measured simultaneously with $D_{\text {a }}$ by fitting chloride profiles. It is a destructive testing method following a particular procedure. It hence corresponds to a complexity level equal to $4.16,10$, and 4 are, respectively, the values of cost, accuracy level, and robustness loss risk. $D_{\mathrm{rcm}}$ can also be measured through auscultation by semidestructive testing [38].

$W_{\text {gel }}$ is the gel content of the cement paste, especially $\mathrm{CSH}$ content when Ordinary Portland Cement (OPC) is used. It can be computed using cement composition and concrete composition through empirical formulas or solving chemical equations. Details are available in [29] and [21]. This requires a good expert knowledge. With a complete building archive (structure A), supplying this parameter corresponds hence to a complexity level equal to 3 . When the cement and concrete compositions are not available in the building archive (structure B), this parameter cannot be supplied through expert advice. Regarding auscultation, this parameter can be measured only through semidestructive testing, following particular experimental procedures such as thermogravimetry [39]. Complexity level is also equal to 4.

$T$ is supplied by climatic chronicles, as well as relative humidity which is used to compute the water content $w$ through sorption/desorption isotherms. When building archive is complete (structure A), sorption/adsorption curve can be found in literature review for a similar concrete (e.g., review by Hansen [40] and Harifidy [41]). A good expert knowledge is required which corresponds to a complexity level equal to 3 . With respect to the structure B (slight building archive), this parameter cannot be supplied through expert advice. Regarding auscultation, $w$ can be measured using nondestructive testing, which corresponds to a complexity level equal to 2 .

$\gamma_{c l}$ is a safety factor which takes into account the scatter in chloride concentration. This parameter cannot be supplied through auscultation but only through expert advice. This needs a good expert knowledge and corresponds hence to a complexity level equal to 3 .

5.1.2. Case of Concrete Carbonation Models. Table 16 reports complexity levels (CL) according to the method used for supplying each model input parameters value, corresponding costs (C), accuracy levels (A), and levels of robustness loss risk (RLR), with respect to structures $A$ and $B$, for the input parameters of concrete carbonation models.

Regarding concrete carbonation, parameters which are available in complete building archive are cement content $c$, concrete composition, and all binder characteristics such as compressive strength $R_{c}$ verified by the compliance test. When these documents are available (structure A), supplying these parameters is quite easy and thus corresponds to 
TABLE 16: Complexity level (CL), cost, accuracy level (A), and the level of robustness loss risk (RLR) with respect to structures A and B and for the input parameters of concrete carbonation models.

\begin{tabular}{|c|c|c|c|c|c|c|c|c|c|c|c|c|c|c|c|c|}
\hline & \multicolumn{8}{|c|}{ Structure A } & \multicolumn{8}{|c|}{ Structure B } \\
\hline & \multicolumn{4}{|c|}{ Expert advice } & \multicolumn{4}{|c|}{ Auscultation data } & \multicolumn{4}{|c|}{ Expert advice } & \multicolumn{4}{|c|}{ Auscultation data } \\
\hline & $\mathrm{CL}$ & $\mathrm{C}$ & A & RLR & $\mathrm{CL}$ & $\mathrm{C}$ & $\mathrm{A}$ & RLR & $\mathrm{CL}$ & $\mathrm{C}$ & $\mathrm{A}$ & RLR & $\mathrm{CL}$ & $\mathrm{C}$ & $\mathrm{A}$ & RLR \\
\hline$c$ & 1 & 1 & 1 & 1 & 4 & 16 & 10 & 4 & 4 & 8 & 4 & 4 & 4 & 16 & 10 & 4 \\
\hline$R_{c}$ & 1 & 1 & 1 & 1 & 2 & 4 & 6 & 2 & 1 & 1 & 1 & 1 & 2 & 4 & 6 & 2 \\
\hline $\mathrm{RH}$ & 1 & 1 & 1 & 1 & 1 & 2 & 4 & 1 & 1 & 1 & 1 & 1 & 1 & 2 & 4 & 1 \\
\hline$T$ & 1 & 1 & 1 & 1 & 1 & 2 & 4 & 1 & 1 & 1 & 1 & 1 & 1 & 2 & 4 & 1 \\
\hline$w / c$ & 1 & 1 & 1 & 1 & 4 & 16 & 10 & 4 & - & - & - & - & 4 & 16 & 10 & 4 \\
\hline$R_{\text {carb }}$ & 2 & 2 & 2 & 2 & - & - & - & - & - & - & - & - & - & - & - & - \\
\hline$n$ & 2 & 2 & 2 & 2 & - & - & - & - & - & - & - & - & - & - & - & - \\
\hline$k_{c}$ & 2 & 2 & 2 & 2 & - & - & - & - & 4 & 8 & 4 & 4 & - & - & - & - \\
\hline$\phi$ & 2 & 2 & 2 & 2 & 3 & 8 & 8 & 3 & 3 & 4 & 3 & 3 & 3 & 8 & 8 & 3 \\
\hline$S_{r}$ & 3 & 4 & 3 & 3 & 3 & 8 & 8 & 3 & 4 & 8 & 4 & 4 & 3 & 8 & 8 & 3 \\
\hline$\rho$ & 2 & 2 & 2 & 2 & 3 & 8 & 8 & 3 & 4 & 8 & 4 & 4 & 3 & 8 & 8 & 3 \\
\hline$\alpha_{\text {hyd }}$ & 2 & 2 & 2 & 2 & 4 & 16 & 10 & 4 & 4 & 8 & 4 & 4 & 4 & 16 & 10 & 4 \\
\hline$k_{e}$ & 2 & 2 & 2 & 2 & 2 & 4 & 6 & 2 & 2 & 2 & 2 & 2 & 2 & 4 & 6 & 2 \\
\hline$k_{t}$ & 2 & 2 & 2 & 2 & 2 & 4 & 6 & 2 & - & - & - & - & 2 & 4 & 6 & 2 \\
\hline
\end{tabular}

the lowest complexity level, i.e., equal to 1 . The corresponding cost $(\mathrm{C})$, accuracy level (A), and level of robustness loss risk (RLR) are all equal to 1 for expert advice. So is it for meteorological data (RH and $T$ ), which can be obtained through climatic chronicles. Regarding the structure B (slight building archive), a theoretical $R_{c}$ is also given. Values of $c$ can be estimated from the knowledge of concrete type and $R_{c}$. Supplying this parameter corresponds hence to complexity level equal to 2, for structure B.

Some other parameters are deduced from the previous ones, such as $R_{\text {carb }}$ or $n$ which values are given in the DuraCrete report [23] according to the type of binder, which is mentioned in a complete building archive (structure A). The complexity for supplying these parameters is hence one level higher than the previous one when assessed from expert advice. This is also the case of $k_{c}$ which can be assessed knowing curing duration. These parameters cannot be supplied through auscultation; therefore, when they are not available in building archive (structure B), the models requiring these parameters cannot be used.

Porosity $\phi$, saturation degree $S_{r}$, density $\rho$, and hydration degree $\alpha_{\text {hyd }}$ can be estimated from expert advice. When the building archive is complete (structure A), these parameters are computed using cement and concrete compositions. However, computations require intermediate models and, for some of them, further additional tools such as adsorption-desorption isotherm curves. When the type of the considered concrete and the type of binder are known through building archive (structure A), curves corresponding to a similar concrete exposed to similar conditions can be used. Regarding structure B, only the concrete type is given, and then, assessments through expert advice are more complicated. Thus, it corresponds to a higher complexity level and a higher cost. However, a higher accuracy is given because more important intellectual investment is required. Regarding auscultation, $\phi$, $S_{r}$, and $\rho$ can be assessed through nondestructive techniques (NDTs). The corresponding complexity level is 2 . The hydration degree $\alpha$ can be obtained only through destructive testing, following a particular procedure [32]. It corresponds to a complexity level equal to 4 .

5.2. Models Costs. The cost of a model, given its input parameters cost, can be assessed as follows:

$$
C_{\text {model }}=\sum C_{i}
$$

where $C_{i}$ is the cost of the parameter $i$. When elaborating maintenance strategy, the manager may face several alternatives regarding the investment he can afford to predict chloride ingress or concrete carbonation. In order to highlight this cost issue and for the sake of comparison between predictive models, various hypotheses are proposed in Table 17. For each hypothesis, some parameters are obtained using measurements, while others are estimated through expert advice. Under the hypothesis $\mathrm{H}_{k}$, measurements are made by destructive or nondestructive tests for all input parameters whose obtaining method has a complexity level equal or less to $(k-1)$; this can be supplied through auscultation, whereas the other input parameters are estimated through expert advice.

The cost of each model according to each hypothesis is presented in Figure 3 for chloride ingress and concrete carbonation models. Not surprisingly, it can be observed that an increase in the number of parameters supplied through auscultation leads to a higher cost. When no variation occurs in the cost from hypothesis $\mathrm{H}_{k}$ to hypothesis $\mathrm{H}_{k+1}$, it means that the maximum number of measurable parameters is already inspected under the hypothesis $\mathrm{H}_{k}$. The cost of a given model is influenced by (i) the number of its input parameters and (ii) the cost of these latter under a given hypothesis.

5.2.1. Structure A. Concerning chloride ingress models under the hypothesis $\mathrm{H}_{1}$ (all parameters supplied through expert advice), the most costly models are Leo and DuraCrete models because they have the highest number 
TABLE 17: Hypothesis on supplying methods.

\begin{tabular}{lcccc}
\hline & & \multicolumn{2}{c}{ Complexity level (Table 14) } \\
\hline Hypothesis & 1 & 2 & 3 & 4 \\
$\mathrm{H}_{1}$ & Expert & Expert & Expert & Expert \\
$\mathrm{H}_{2}$ & Auscultation & Expert & Expert & Expert \\
$\mathrm{H}_{3}$ & Auscultation & Auscultation & Expert & Expert \\
$\mathrm{H}_{4}$ & Auscultation & Auscultation & Auscultation & Expert \\
$\mathrm{H}_{5}$ & Auscultation & Auscultation & Auscultation & Auscultation \\
\hline
\end{tabular}
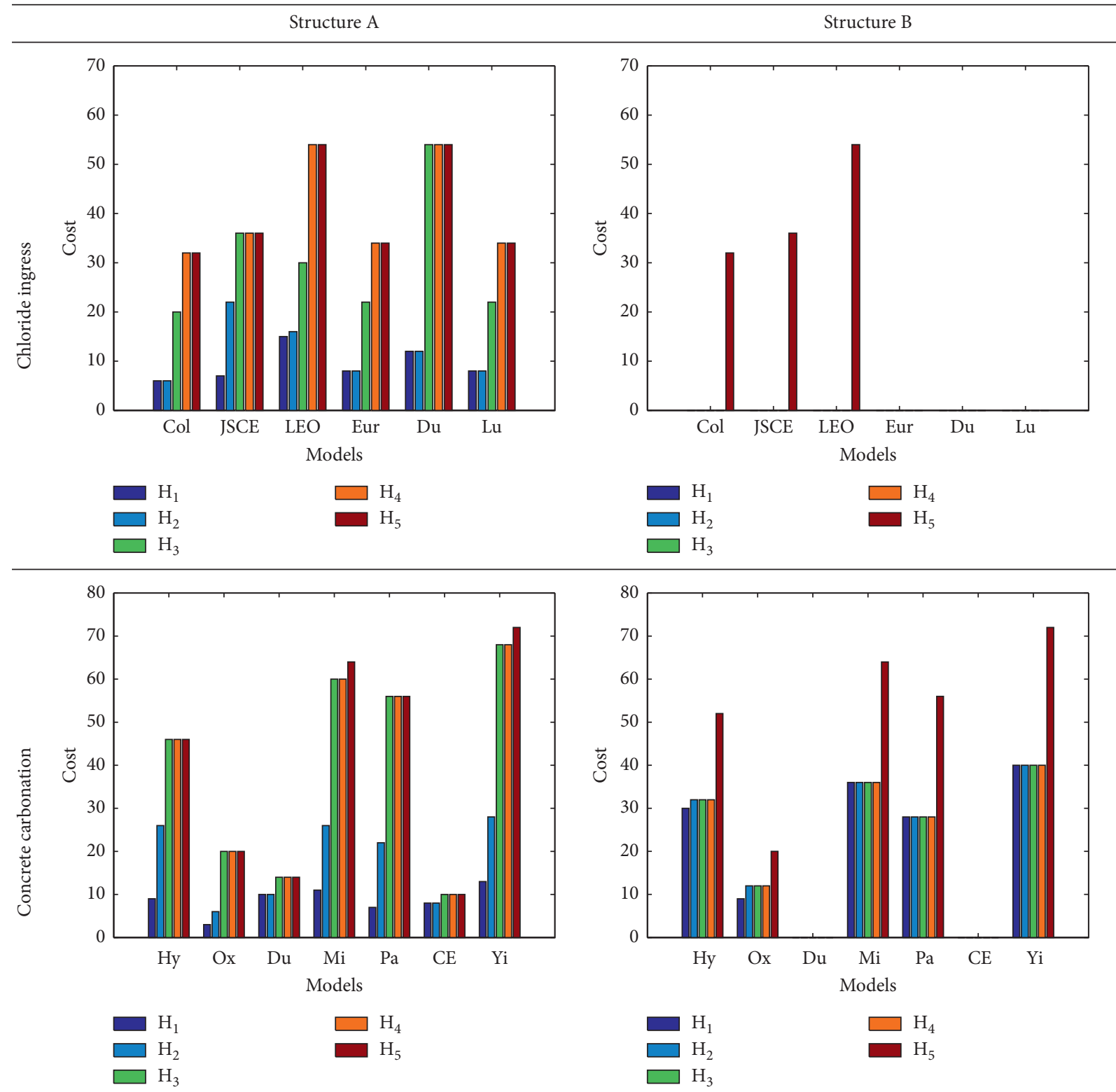

FIgURE 3: Cost of each model according to each hypothesis for structure A and structure B.

of input parameters. The Leo model cost is slightly higher due to the fact that it contains more costly parameters such as $w$ and $W_{\text {gel }}$. When passing to hypothesis $\mathrm{H}_{2}$, JSCE model becomes the most costly. Indeed, under this hypothesis, $w / c$ which is one of its input parameters is to be supplied through auscultation. This leads to increasing its cost. Under the hypothesis $\mathrm{H}_{3}, C_{s}$ and $D_{\mathrm{rcm}}$ are to be supplied through auscultation, in addition to those measured under $\mathrm{H}_{2}$. The DuraCrete model is the only model that requires $D_{\mathrm{rcm}}$; therefore, it becomes the most 
costly. From $\mathrm{H}_{4}$ to $\mathrm{H}_{5}$, the Leo model increases in cost because $w$ and $W_{\text {gel }}$ are inspected.

Concerning carbonation models, one observes lower values of cost for DuraCrete and CEB models. This is due to the fact that these models involve few parameters that can be obtained through auscultations ( $\mathrm{RH}$ through the parameter $\left.k_{e}\right)$. Models of Ying-Yu and Miragliotta are the most costly ones since they contain the highest number of input parameters that can be supplied through auscultations.

5.2.2. Structure B. Regarding structure B, some parameters, such as $n, \alpha$, and $k_{c}$ for chloride ingress and $R_{\text {carb }}$ and $k_{c}$ for concrete carbonation models, cannot be supplied neither through expert advice (slight building archive) nor through auscultation. Therefore, the models which require these parameters cannot be used. These are EuroLightCon, DuraCrete, and Luping for chloride ingress and DuraCrete and Oxand for concrete carbonation. Concerning chloride ingress models, all the other parameters except the temperature $T$ can only be supplied through auscultation and, therefore, under hypothesis $\mathrm{H}_{5}$. The Leo model is the most costly model because it has the highest number of parameters. Regarding concrete carbonation models, the Oxand model has the lowest cost because it involves the fewer number of input parameters. The next section will thus analyze the balance between the cost of a model and its benefit.

\section{Assessment of Benefit}

Obtaining a given input model parameter value is a gain for the prediction process and therefore for the maintenance strategy. The higher the complexity level of the method used for supplying, the higher the accuracy level of the obtained value. Indeed, complex methods are generally advanced methods. However, a higher complexity level implies higher risk with respect to the method robustness. The gain of a given input parameter accounts hence for accuracy level and level of robustness loss risk. An assessment of this gain is proposed in the current section. The global gain of a given model, so named benefit in this work, is the sum of the gain of its input parameters. Thus, the benefit of a given model depends on the relative importance of each input parameter. It could be deduced erroneously that the model which provides the highest benefit is the most interesting one. Indeed, model costs should also be accounted for and could moderate its interest.

\subsection{Methodology}

6.1.1. Weighting of the Sensitivity Indicators. As above mentioned, the sensitivity indicators do not play the same role with respect to model parameters. It is therefore necessary to moderate these sensitivity indicators in order to use them in a combined way. For this sake, we weight each indicator with respect to the information that they could provide. Within this study, we do the weighting process qualitatively. Consequently, we assume some arbitrariness in the definition of the weighting factors. They are reported in Table 18.

We affect the highest factor for the output's standard deviation. Indeed, it provides a quantification of the variation in output when a given input randomly varies. It is hence an assessment of the uncertainty on the output of the model when we take into account the uncertainty of the studied input. In other words, it is a quantification of the uncertainty transfer from a given input to the model output. Elasticity coefficient and bias on the mean are almost equivalent; however, a higher weight is given to the elasticity coefficient because it accounts for a more direct assessment. Pearson's coefficient is less meaningful for degradation processes because it supposes the linearity of the model with respect to its input parameters.

In order to better differentiate the importance of the parameters with respect to their impact on the model output, we introduce for each parameter an importance factor depending on the weighted sensitivity indicators and the normalized mark of the parameter among others for a given sensitivity indicator. We propose the following procedure for weighting the sensitivity results:

(i) The mark $N_{X, i}$ of the parameter $i$ according to the indicator $X(X=|E|,|P|,|M|$, Std. $)$ is computed as a normalized mark:

$$
N_{X, i}=\frac{X_{i}}{\sum_{j=1}^{n_{j}} X_{j}},
$$

where $i$ indicates the $i^{\text {th }}$ parameter and $n_{j}$ is the number of input parameters of the considered model.

(ii) Then, the normalized importance factor $\left(\sum_{i} F_{i}=1\right)$ for each parameter is given as follows:

$$
F_{i}=\sum_{X} N_{X, i} w_{X}
$$

where $w_{X}$ is the weighting of the indicator $X$ reported in Table 18 .

6.1.2. Ranking. Independently from the approach applied to assess or supply a model parameter, its knowledge constitutes a gain in the maintenance strategy at the prediction stage. The gain brought by a parameter in the use of a given model depends obviously on the level of accuracy of its evaluation (A). Nevertheless, this gain can be also weakened because the overall procedure employed to evaluate the parameter is elaborate and uncertain and leads to a possible risk of lack of robustness. Therefore, the gain of a parameter $i$ can be expressed as

$$
G_{i}=\frac{A_{i}}{\mathrm{RLR}_{i}} .
$$

Once the input parameters have been supplied, using a given model can be characterized by a brought benefit stated as 
TABLE 18: Weighting factors.

\begin{tabular}{lc}
\hline Sensitivity indicators $(X)$ & Weighting $\left(w_{X}\right)$ \\
\hline Elasticity coefficient & 0.3 \\
Pearson's coefficient & 0.1 \\
Bias on the output's mean & 0.2 \\
Output's standard deviation & 0.4 \\
\hline
\end{tabular}

$$
\text { Ben }_{\text {model }}=\sum F_{i} G_{i}
$$

where $F_{i}$ is the importance factor of the parameter $i$ given by equation (6).

The benefit of a given model, under a given hypothesis, is firstly influenced by the gain provided by the knowledge of each of its input parameters, as defined in equation (7), and then by the relative importance of these input parameters. As shown through sensitivity analysis, the prominent parameters change with time and are different for each considered material.

6.2. Benefit of Chloride Ingress Models. In order to illustrate the methodology with chloride ingress models, benefits of each model according each hypothesis are plotted in Figure 4 for concretes C45, C35, and C25 at $2.5 \mathrm{~cm}$ depth and after 50 years of exposure.

6.2.1. Benefit of Models for Structure A. With respect to structure A, it is highlighted that an increase in auscultation data provides more benefit to the model response. A first model ranking can be observed. Under hypothesis $H_{1}$, the JSCE model appears to provide the highest benefit for all considered concretes. Indeed, at 50 years, the prominent parameters are those which take into account environmental conditions such as $C_{s}, \gamma_{c l}$, and T. The JSCE model is the only model which uses $\gamma_{c l}$. Moreover, the complexity level of the method used for supplying this parameter is equal to 3 (Table 15). This increases the gain provided by the knowledge of this parameter and hence the benefit of the model. Under hypothesis $\mathrm{H}_{2}$, differences can be observed for each concrete. With respect to $\mathrm{C} 45$, the LEO model provides the highest benefit, while it is still the JSCE model for C35 and C25. Under $\mathrm{H}_{2}, w / c$ (a material parameter of JSCE) and $T$ (an environmental parameter of LEO) are measured through auscultation. However, the JSCE model is more sensitive to environmental parameters at 50 years. Moreover, among models of the first group, the LEO model is more sensitive to material parameters when material has good mechanical performance (C45). Consequently, the LEO model has a higher benefit when applied to concrete $\mathrm{C} 45$. With respect to hypothesis $\mathrm{H}_{3}, \mathrm{C}_{s}$ is measured through auscultation. The JSCE model provides the highest benefit because this model has two environmental parameters $\left(C_{s}\right.$ and $\left.\gamma_{c l}\right)$ which are prominent at 50 years and involve complex methods for supplying. Regarding $\mathrm{H}_{4}$ and $\mathrm{H}_{5}$, the LEO model provides the highest benefit since this model has the highest number of parameters which can be supplied through auscultation. Indeed, according to this approach, the accuracy level of a given parameter value and, hence, the benefit of the corresponding model is higher when it is measured through auscultation.

6.2.2. Benefit of Models for Structure B. With respect to structure B, as explained previously, EuroLightCon, DuraCrete, and Luping models cannot be used because some of their input parameters cannot be supplied, and the other models can be run only under hypothesis $\mathrm{H}_{5}$. The LEO model provides the highest benefit for each considered concrete because it has the highest number of parameters which can be supplied through auscultation. With respect to the JSCE model, a slightly lower benefit can be observed for concretes $\mathrm{C} 35$ and $\mathrm{C} 25$. Under $\mathrm{H}_{5}$, all measurable parameters are supplied through auscultation. Supplying $w / c$ through this method is more complex than supplying $\gamma_{c l}$ (Table 15). However, the model is less sensitive with respect to $w / c$ when applied to C35 and C25. Moreover, sensitivity of the model to environmental parameters $C_{s}$ is more pronounced for these materials and at advanced age (25 and 50 years). Therefore, the gain provided by the knowledge of this parameter and hence the benefit of the model is less important.

6.3. Benefit of Concrete Carbonation Models. As well as for chloride ingress, in order to illustrate the methodology, an example is presented for concrete carbonation models when applied to concrete C45 in Figure 5 after 50 years of exposure.

As expected, it can be seen that a rise of benefit is experienced as long as auscultation data are provided. However, from $\mathrm{H}_{2}$ to $\mathrm{H}_{5}$, no significant difference can be observed. Indeed, the increase in accuracy is compensated by the increase in robustness loss risk. Due to the important lack of information in the building archive of structure B, the benefit granted when auscultations are performed (especially from hypothesis $\mathrm{H}_{1}$ to $\mathrm{H}_{2}$ ) is larger for this structure than for structure A. It is to be noted that, for structure B, the use of DuraCrete model or CEB model to predict carbonation is not possible because some input parameters of these models cannot be supplied through auscultation.

\section{Models Efficiency}

Similarly to a cost-benefit approach it is now possible to rank the models on the basis of the so-called model efficiency, computed as the ratio of the variation in benefit $\Delta \mathrm{Ben}_{\text {model }}$ over the variation in cost $\Delta C_{\text {model }}$ when passing from hypothesis $\mathrm{H}_{1}$ (no auscultation) to $\mathrm{H}_{5}$ (full auscultation):

$$
\text { Eff }=\frac{\Delta \text { Ben }_{\text {model }}}{\Delta C_{\text {model }}} .
$$

7.1. Efficiency of Chloride Ingress Models. Concerning chloride ingress models, the efficiency for all models in the case of structures A and B and with respect to concretes C45, $\mathrm{C} 35$, and C25 after 10, 25, and 50 years of exposure is presented in Figure 6. The model which provides the 


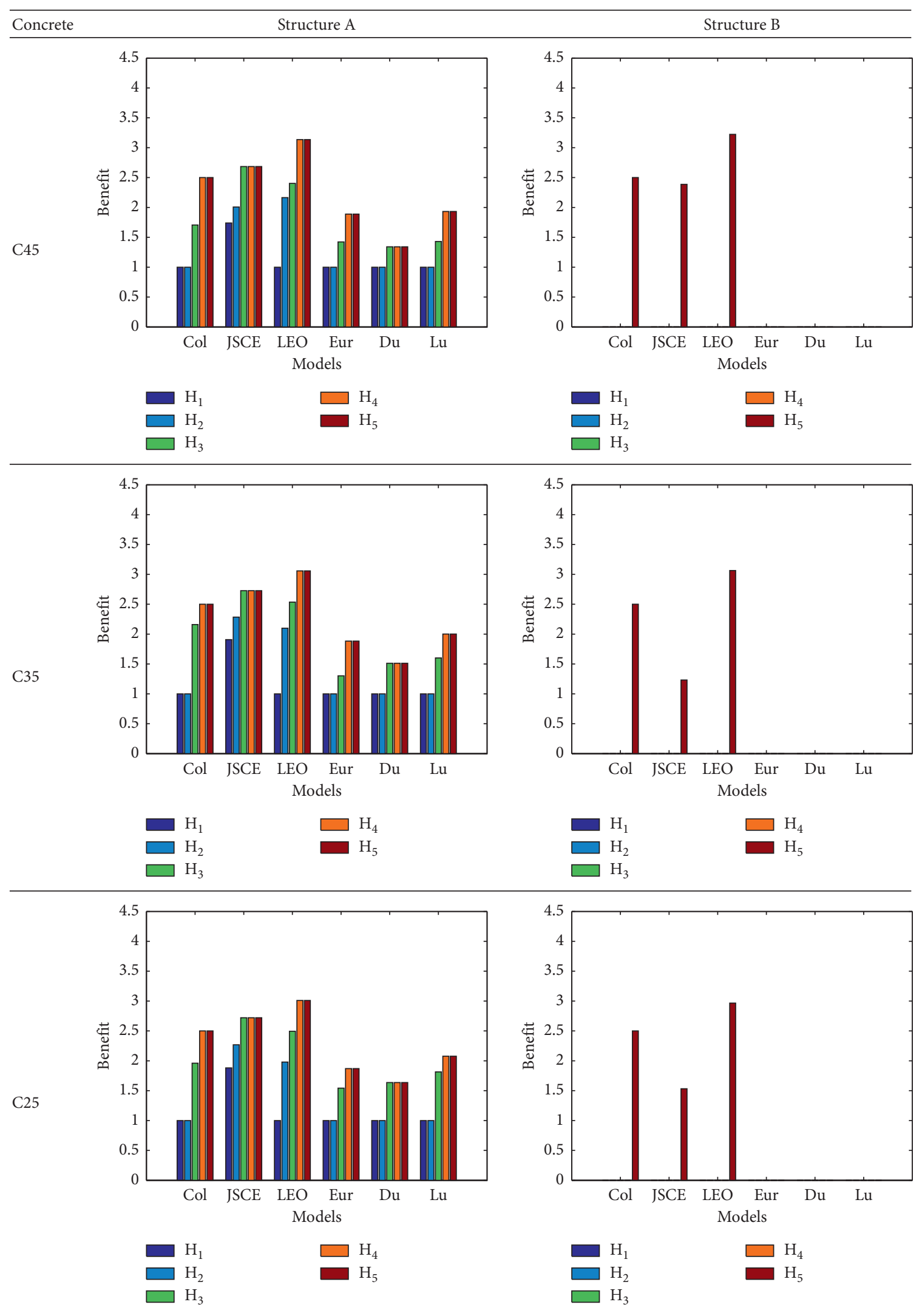

Figure 4: Benefit of each chloride ingress model according to each hypothesis for structure A and structure B. 


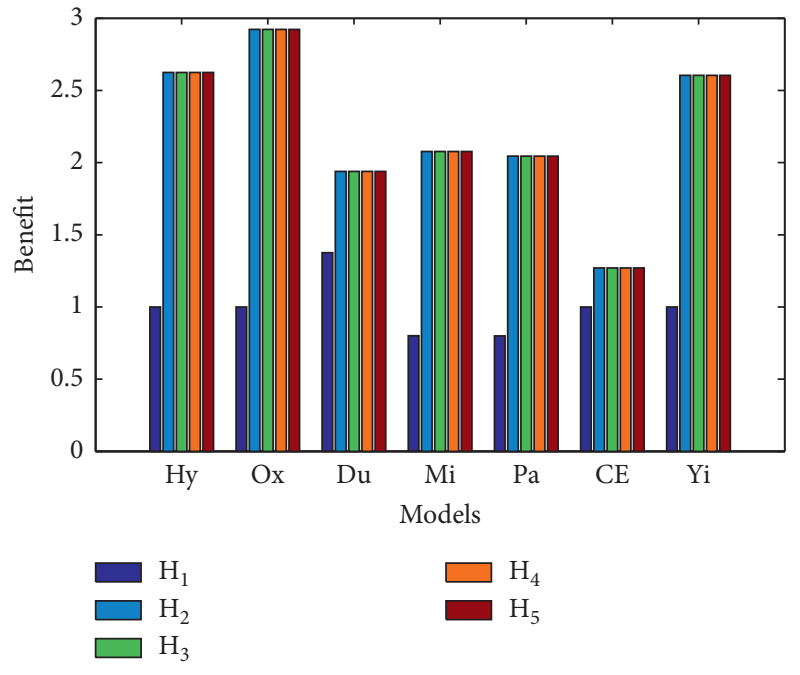

(a)

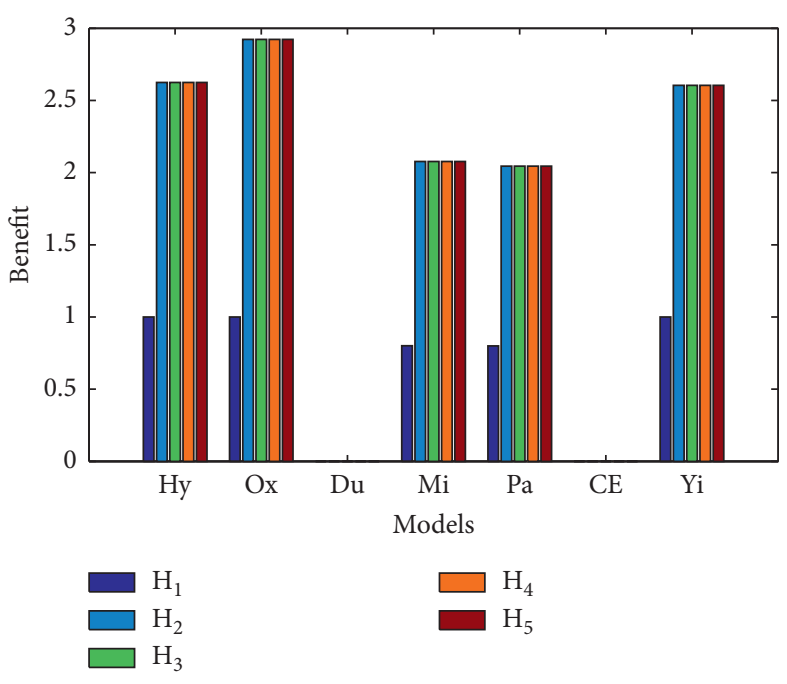

(b)

FIgURE 5: Benefit of each concrete carbonation model according to each hypothesis for structure A (a) and structure B (b).

maximum efficiency can be deemed as the best model according to the proposed procedure.

\subsubsection{Efficiency for Structure A. Regarding structure A, with} respect to models ordering, slight differences can be observed between material with good performance (C45) and other ones (C35 and C25). This is due to the fact that prominent parameters are different for materials with good or ordinary quality. With respect to the first category (C45), models are more sensitive to material parameters. This is more underlined at early age (10 years). At advanced age, environmental parameters become more prominent. Therefore, models which involve a high number of material input parameters with a high relative importance provide a higher efficiency. On the contrary, regarding C35 and C25, models are more sensitive to environmental parameters. This is even more pronounced at advanced ages.

As a result, Leo model appears to be the best model at 10 years for concrete C45. However, at 25 and 50 years, it becomes the second one behind the Collepardi model. Due to the same trends, JSCE is the fourth model regarding models ordering at 10 and 25 years and becomes the fifth one at 50 years behind EuroLightCon model. For all considered materials, the efficiency of JSCE and Leo models decreases over time because these models have material input parameters which provide a higher gain when inspected. Indeed, the accuracy level of $w / c$ value (JSCE input parameter) is equal to 16 when it is inspected, while it drops to 1 through expert advice (Table 15). Accuracy level of the $W_{\text {gel }}$ value raises from 3 to 10 when it is inspected (Table 15). However, these parameters become less important at advanced age. This leads to reduce the benefit and hence the model efficiency. The efficiency of the Collepardi model does not change over time due to the fact that it has only two parameters, and environmental conditions are taken into account only through one of them $\left(C_{s}\right)$. Indeed, in the case of two parameters, a decrease in relative importance of one parameter implies an increase in the second one's. Therefore, no significant differences of the model benefit, and hence, efficiency can be observed.

Regarding the models of the second group (models with time-dependent parameters: EuroLightCon, DuraCrete, and Luping), models efficiency increases over time and when material is of poor quality. The main material parameters that can be supplied through auscultation are $D_{\text {ar }}$ and $D_{\text {rcm }}$. The accuracy level of their values passes from 3 to 10 and 2 to 10, respectively, when inspected (Table 15). The accuracy level of the main environmental parameter value $C_{s}$ passes from 2 to 10 when inspected (Table 15). Therefore, the gain provided by $C_{s}$ is at least equal to those provided by $D_{\mathrm{ar}}$ and $D_{\text {rcm }}$. Then, when environmental parameters are prominent (less quality and advanced age), the efficiency is higher except for EuroLightCon model. Regarding this latter, the parameter $\alpha$ has a larger variation interval width (Table 8) with respect to $\mathrm{C} 25$, when compared to the two other materials. Consequently, it has a higher relative importance. This explains the observed trend. The DuraCrete model provides the lowest efficiency because it has the lowest measurable parameters through auscultation.

7.1.2. Efficiency for Structure B. Regarding structure B, a higher efficiency can be observed for models whose material input parameters bring a higher gain when supplied through auscultation, in the case of the concrete $\mathrm{C} 45$ and at early age. JSCE model appears to be the best at 10 years, and it comes down to second place at 25 and 50 years. $w / c$ (JSCE input parameter) provides the highest gain when supplied through auscultation. Indeed, its accuracy level passes from 1 to 10 (Table 15$)$. Therefore, at early age (10 years), when models are more sensitive to material parameters, the JSCE model provides the highest efficiency. At advanced age, the sensitivity to material parameters decreases. This low efficiency is even more significant for the JSCE model when applied to C35 and C25 because of low relative importance of material 

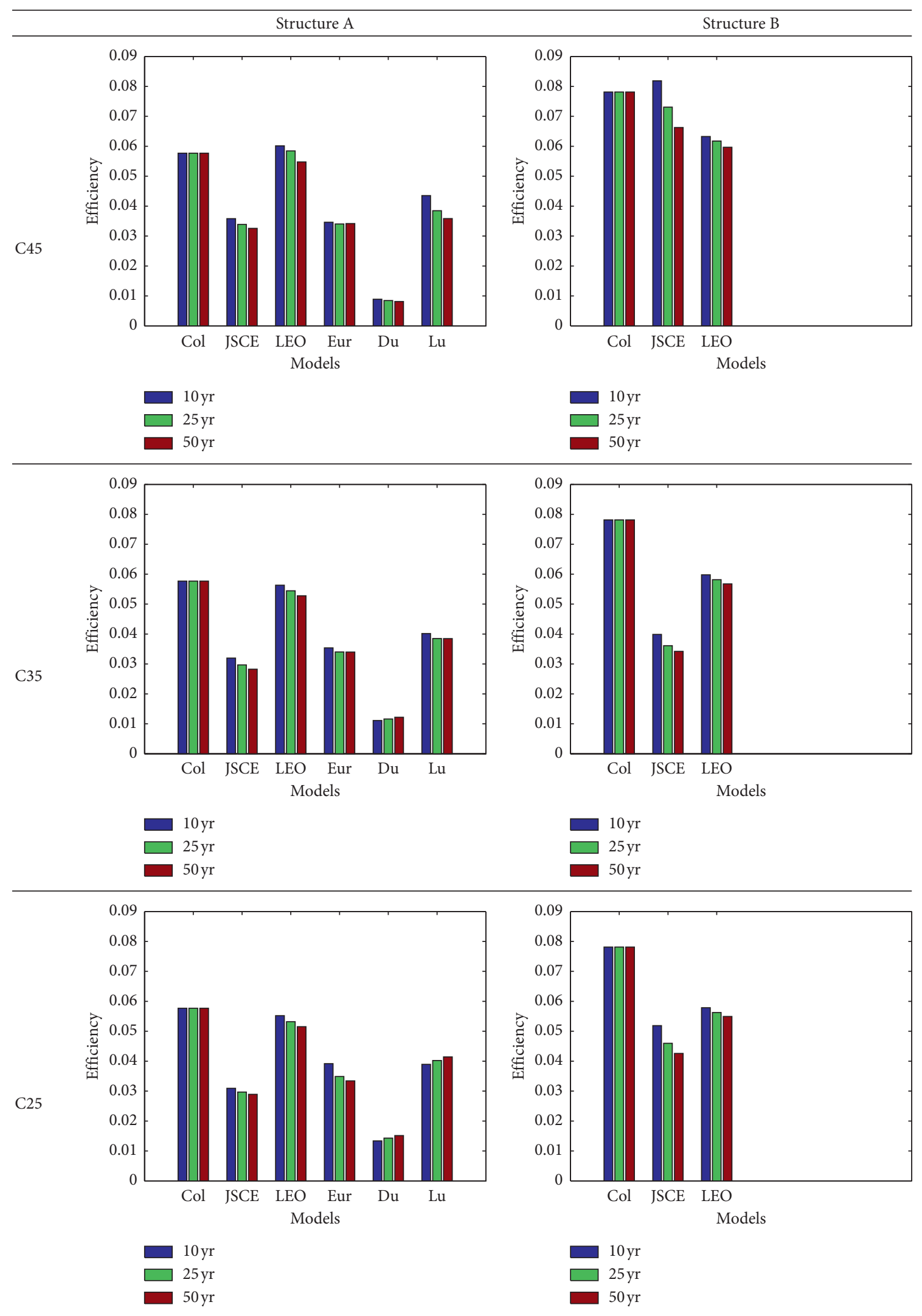

FIGURE 6: Efficiency of each chloride ingress model according to each hypothesis for structure A and structure B. 


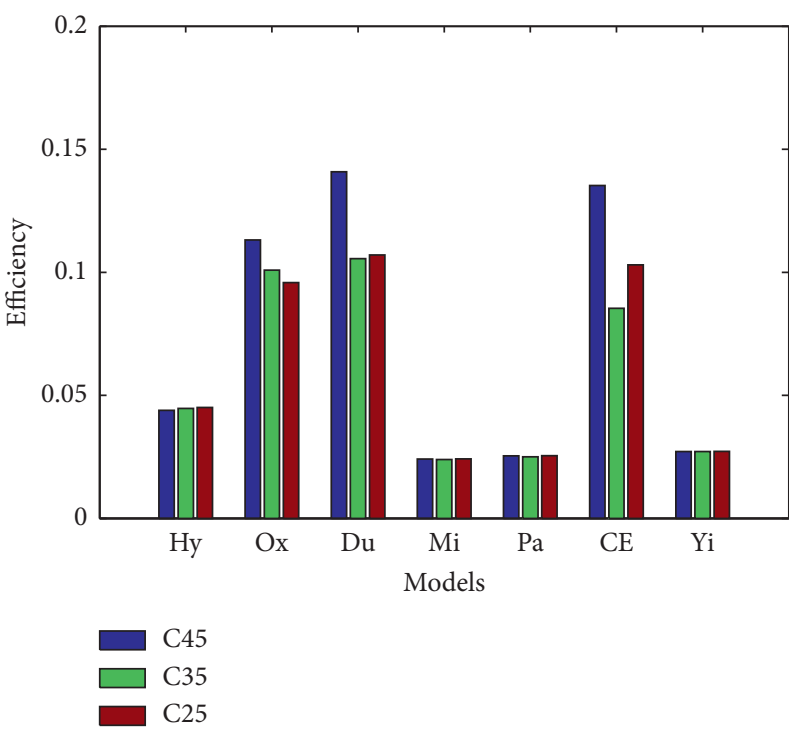

(a)

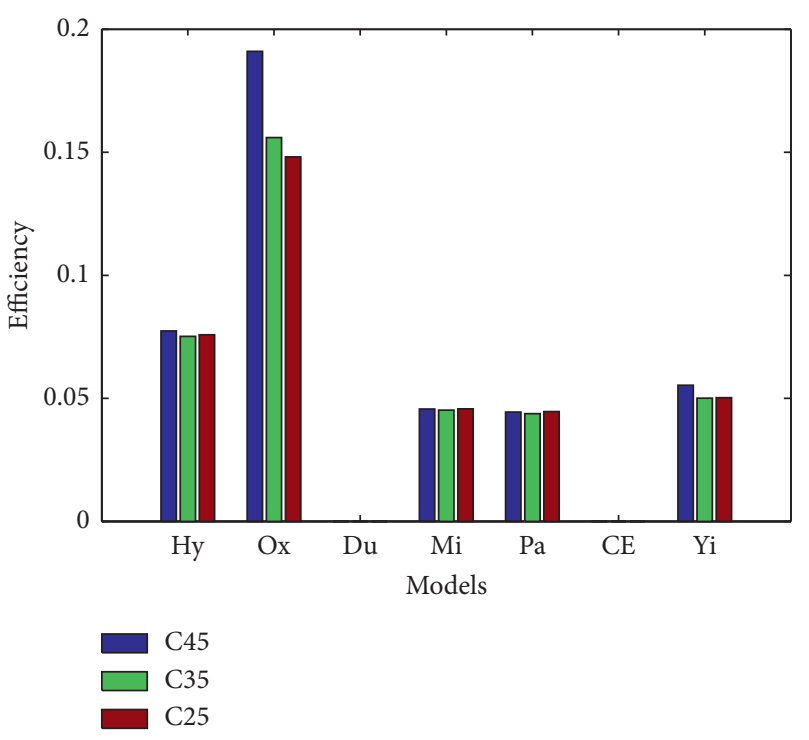

(b)

FIGURE 7: Efficiency of each concrete carbonation model when applied to concretes C45, C35, and C25 for structure A (a) and for structure B (b).

parameters. The Collepardi model appears to be better than LEO model. This latter involves the highest number of measurable input parameters that can increase its benefit, and the Collepardi model the lowest. However, supplying many parameters through auscultation can increase the model cost and then decrease its efficiency.

\subsection{Efficiency of Concrete Carbonation Models.} Concerning concrete carbonation, the models efficiency in the case of structures A and B, with respect to concretes C45, C35, and C25, is presented in Figure 7.

7.2.1. Efficiency for Structure A. Concerning structure A, DuraCrete and CEB models provide the maximum efficiency, and they could be deemed as the more suitable ones in the maintenance strategy for this structure. Indeed, most of input parameters of these models are supplied using building archive which is quite complete for this structure. The ordering of models is the same for each considered concrete. However, value of efficiency is different for each concrete due to the difference of relative importance of each parameter for each concrete, given by sensitivity analysis.

7.2.2. Efficiency for Structure B. Regarding to structure B, the Oxand model appears as the most suitable model in the maintenance strategy. For the DuraCrete and CEB models, no efficiency factor could be computed because some input parameters $\left(R_{\text {carb }}\right.$ and $\left.n\right)$ cannot be assessed without complete building archive. The values of models efficiency with respect to this structure are higher than the ones estimated for structure A. For some models and some concretes, the difference is significant, e.g., Oxand and Hyvert models with respect to C45 concrete. For this structure, due to a lack of information, obtaining parameters through expert advice requires more complex and hence more costly methods. Therefore, under hypothesis $\mathrm{H}_{1}$ (all parameters are estimated through expert advice), the cost of each model is already higher. Consequently, concerning this structure B, the value of $\Delta C_{\text {model }}$ (difference between the model cost under hypothesis $\mathrm{H}_{5}$ and $\mathrm{H}_{1}$ ) is lower for each model. Thus, the value of efficiency (equation (9)) is higher. As for structure $\mathrm{A}$, the ordering of the models with respect to efficiency for structure B is the same for the 3 considered concretes.

The results for the two considered structures highlight that models ranking could be completely different from a structure to another one, depending on the available data and prerequisite information. When complete building archive is available, depending on the manager objectives, several strategies can be adopted for supplying input parameters. When this document is not complete, auscultations are of utter importance. When considering several materials, differences can be observed in the values of efficiency. However, the models ordering is not modified.

\section{Conclusions}

Predicting the evolution of carbonation depth or chloride ingress into concrete structures by using deterioration models is an essential task for formulating a comprehensive maintenance strategy. The determination of input parameters of the models for such a purpose may be therefore a major concern. Two approaches can be followed: (i) the expert advice, where the available information is used without producing any new data, including experimental and (ii) auscultation (nondestructive or semidestructive testing) within which an experimental investigation provides new data for determining the input parameters. 
The cost of a given model can be defined as the sum of the costs of its input parameters. The cost of each input parameter depends on the method used for obtaining it. In this paper, we assume that the value of a given parameter has better quality when it has been obtained by auscultation (destructive or nondestructive tests) than when it is assessed by expert advice. On the contrary, we also assume that carrying out an experimental investigation has a higher cost than assessing through expert advice. Given that each model does not involve the same input parameters and that some parameters cannot be supplied through auscultation, each model does not have the same sensitivity to the auscultation method. According to the available data, requiring to auscultation is more or less significant. The methodology proposed in this work aims at displaying the most suitable chloride ingress and concrete carbonation model for (i) a given structure characterized by the amount of available data and (ii) resource allocated to auscultation.

The approach developed in this study relies on the combination of the abovementioned items (ranking of parameters, data availability, and allocated resources) for calculating the efficiency of the models. Depending on the available data, the most efficient model is different. Similarly, it appears that the concrete type can influence the efficiency of the models because of their sensitivity to variable material parameters. The proposed methodology could be an helpful tool for building and infrastructure managers in the choice of the appropriate model to their structure. Finally, it can be extrapolated to other degradation models involved in an auscultation maintenance strategy analysis.

This study is a first attempt for selecting models according to a cost/benefit analysis combining physical and pseudoeconomical aspects throughout weighting factors. However, as for all types of approach where qualitative weighting factors are employed, a selection is based on a minimum arbitrariness. Further research should focus on a more robust way to define these weighting factors under particular financial context.

\section{Nomenclature}

$\begin{array}{ll}x: & \text { Distance from the concrete surface } \\ C(x, t): & \text { Chloride content at distance } x \text { from the } \\ & \text { concrete surface and at time } t \\ \xi: & \text { Concrete diffusivity } \\ \mathbf{X}: & \text { Vector of input parameters that are specific to } \\ & \text { each model } \\ k(\xi(\mathbf{X}, t), x): & \text { Chloride ingress model factor } \\ C_{\text {ini }}: & \text { Initial chloride content of the concrete } \\ k_{\text {exe }}: & \text { Factor which introduces execution conditions } \\ k_{\text {exp }}: & \text { Factor which introduces exposure conditions } \\ k_{P}: & \text { Factor which introduces phenomenon that } \\ & \text { could influence the diffusion coefficient of the } \\ & \text { carbon dioxide into concrete porosity } \\ k_{P, M}: & \text { Part of } k_{P} \text { associated with material properties } \\ k_{P, E}: & \text { Part of } k_{P} \text { associated with environmental } \\ D_{\mathrm{CO}_{2}}: & \text { properties } \\ C_{0}: & \text { Diffusion coefficient of carbon dioxide } \\ & \text { Carbon dioxide content }\end{array}$

$P_{\text {atm }}$ :

$a:$

$a^{\prime}:$

$C_{\mathrm{abs}}$ :

$t_{0}:$

$t_{c}$ :

$R_{\text {carb }}$ :

$k_{c}$ :

$\rho:$

$C_{s}$ :

$D_{\mathrm{a}}$ :

$D_{\text {ar }}$ :

$t_{r}:$

$\gamma_{c l}$ :

$n:$

$\alpha:$

$k_{t}$ :

$k_{e}$ :

$D_{\text {rcm }}$ :

$a_{i}:$

$b_{i}$ :

$C_{i}$ :

$C_{\text {model }}$ :

$N_{X, i}$ :

$n_{j}$ :

$F_{i}$ :

$A_{i}$ :

$G_{i}$ :

$\mathrm{RLR}_{i}$ :

Ben $_{\text {model }}$ :

Ben:

$\triangle$ Ben:

$\Delta C_{\text {model }}$ :

Eff:

$R_{c}$ :

$S_{r}$ :

$w:$

$w / c:$

$W_{\text {gel }}$ :

$w_{X}$ :

$\mathrm{RH}$ :

$D_{a_{\mathrm{JSCE}}}$ :

$P_{\mathrm{CO}_{2}}$ :

T:

$\phi$ :

$S_{r}$ :
Atmospheric pressure

Quantity of carbonatable material into the concrete

Required quantity of $\mathrm{CO}_{2}$ for a complete

carbonation of the material

Quantity of absorbed carbon dioxide

Reference time

Cure duration

Ability of the considered concrete, in resisting carbonation

Input parameter which assesses the cure condition effects

Density

Chloride content on the exposed surface of the concrete

Apparent diffusion coefficient of chloride

Apparent diffusion coefficient of chloride at reference time $t_{r}$

Reference time

Safety factor in the JSCE model

Aging parameter

Aging parameter for the model of

EuroLightCon

Test method parameter

Parameter which assesses environmental

condition effects

Migration coefficient of chloride

Lower bound of the variation interval

Upper bound of the variation interval

Parameter cost

Model cost

Note of the parameter $i$ according to the indicator $X$

Number of input parameters

Importance factor of the parameter $i$

The level of accuracy of the evaluation of the parameter $i$

Parameter gain

Risk of loss of robustness of the method

chosen to evaluate the parameter $i$

Model benefit

Benefit

Variation in benefit

Variation in cost

Efficiency

Concrete compressive strength

Saturation degree

Water content

Water to cement ratio

$\mathrm{CSH}$ content

Weighting of sensitivity indicator $X$

Relative humidity

Empirical formula to determine diffusion

coefficient in the model of JSCE for OPC [20]

Pressure of $\mathrm{CO}_{2}$

Temperature

Porosity

Saturation degree 


$\begin{array}{ll}\text { CSH: } & \text { CSH content } \\ \text { CH: } & \text { Portlandite content } \\ \text { AFt: } & \text { AFt content } \\ \text { AFm: } & \text { AFm content } \\ \left(\mathrm{C}_{3} \mathrm{~S}\right) \mathrm{C}_{3}: & \text { S content } \\ \left(\mathrm{C}_{2} \mathrm{~S}\right) \mathrm{C}_{2}: & \text { S content } \\ \left(\mathrm{C}_{3} \mathrm{~A}\right) \mathrm{C}_{3}: & \text { A content } \\ \left(\mathrm{C}_{4} \mathrm{AF}\right) \mathrm{C}_{4}: & \text { AF content } \\ \alpha_{\text {hyd }}: & \text { Hydration degree } \\ \alpha_{1}, n_{1}: & \text { Adjusting parameters of the model of Hyvert. }\end{array}$

\section{Data Availability}

The data used to support the findings of this study are available from the corresponding author upon request.

\section{Conflicts of Interest}

The authors declare that they have no conflicts of interest.

\section{Acknowledgments}

This study was carried out in the framework of the research project EvaDeOS (French National Research Agency (ANR 2011-VILD-002-01)). All partners of this project are gratefully acknowledged.

\section{References}

[1] A. Strauss, K. Bergmeister, S. Hoffmann, R. Pukl, and D. Novak, "Advanced life-cycle analysis of existing concrete bridges," Journal of Materials in Civil Engineering, vol. 20, no. $1,2008$.

[2] P. K. Behera, A. P. K. Moon, K. Mondal, and S. Misra, "Estimating critical corrosion for initiation of longitudinal cracks in rc structures considering phases and composition of corrosion products," Journal of Materials in Civil Engineering, vol. 28, no. 12, 2016.

[3] A. A. Torres-Acosta and M. Martinez-Madrid, "Residual life of corroding reinforced concrete structures in marine environment," Journal of Materials in Civil Engineering, vol. 15, no. 4, pp. 344-353, 2003.

[4] S. Tesfamariam, E. Bastidas-Arteaga, and Z. Lounis, "Seismic retrofit screening of existing highway bridges with consideration of chloride-induced deterioration: a bayesian belief network model," Frontiers in Built Environment, vol. 4, pp. 1-11, 2018.

[5] E. Bastidas-Arteaga, C.-P. El Soueidy, O. Amiri, and P. T. Nguyen, "Polynomial chaos expansion for lifetime assessment and sensitivity analysis of reinforced concrete structures subjected to chloride ingress and climate change," Structural Concrete, pp. 1-12, 2020.

[6] E. Bastidas-Arteaga and F. Schoefs, "Stochastic improvement of inspection and maintenance of corroding reinforced concrete structures placed in unsaturated environments," Engineering Structures, vol. 41, pp. 50-62, 2012.

[7] E. Bastidas-Arteaga and F. Schoefs, "Sustainable maintenance and repair of RC coastal structures," Proceedings of the Institution of Civil Engineers-Maritime Engineering, vol. 168, no. 4, pp. 162-173, 2015.
[8] M. H. Faber and J. D. Sorensen, "Indicators for inspection and maintenance planning of concrete structures," Structural Safety, vol. 24, no. 2-4, pp. 377-396, 2002.

[9] H. M. Imounga, E. Bastidas-Arteaga, R. Moutou Pitti, S. Ekomy Ango, and X.-H. Wang, "Bayesian assessment of the effects of cyclic loads on the chloride ingress process into reinforced concrete," Applied Sciences, vol. 10, no. 6, p. 2040, 2020.

[10] A. O'Connor, E. Shelse, E. Breysse, and F. Schoefs, "Markovian bridge maintenance planning incorporating corrosion initiation and non-linear deterioration," Journal of Bridge Engineering, vol. 18, no. 3, pp. 189-199, 2013.

[11] N. Rakotovao Ravahatra, F. Schoefs, F. Duprat, T. de Larrard, and E. Bastidas-Arteaga, "Assessing the capability of analytical carbonation models to propagate uncertainties and spatial variability of reinforced concrete structures," Frontiers in Built Environment: Bridge Engineering, vol. 3, no. 1, pp. 1-9, 2017.

[12] H. Kuhn, "Extensive games and the problem of information," Contributions to the Theory of Games, Vol. II, Princeton University Press, Princeton, NJ, USA, 1953.

[13] R. L. Stratonovich, "On value of information," Izvestiya of USSR Academy of Sciences, Technical Cybernetics, vol. 5, pp. 3-12, 1965, In Russian.

[14] A. Daneshkhah, N. G. Stocks, and P. Jeffrey, "Probabilistic sensitivity analysis of optimised preventive maintenance strategies for deteriorating infrastructure assets," Reliability Engineering \& System Safety, vol. 163, pp. 33-45, 2017.

[15] A. Zitrou, T. Bedford, and A. Daneshkhah, "Robustness of maintenance decisions: uncertainty modelling and value of information," Reliability Engineering \& System Safety, vol. 120 , pp. $60-71,2013$.

[16] A. V. Saetta, "Deterioration of reinforced concrete structures due to chemical-physical phenomena: model-based simulation," Journal of Materials in Civil Engineering, vol. 17, no. 3, 2005.

[17] N. Rakotovao Ravahatra, E. Bastidas-Arteaga, F. Schoefs, T. de Larrard, and F. Duprat, "Probabilistic and sensitivity analysis of analytical models of corrosion onset for reinforced concrete structures," European Journal of Environmental and Civil Engineering, pp. 1-30, 2019.

[18] N. Rakotovao Ravahatra, T. de Larrard, F. Duprat, E. BastidasArteaga, and F. Schoefs, Consistent Set of Random Variables for Characterizing Properties of 3 Concrete Types in Chloride and Carbonation Environment, Report No. 1, MRGenci-Rep2016, MRGenCi reports and Publications, 2016.

[19] M. Collepardi, A. Marcialis, and R. Turriziani, "The kinetics of chloride ions penetration in concrete," Il Cemento, vol. 67, pp. 157-164, 1970.

[20] JSCE, Proposed Specification of Durability Design for Concrete Structures, Report No. 15, Japan Society of Civil Engineers, Tokyo, Japan, 2007.

[21] I. Petre-Lazar, évalation du comportement en service des ouvrages en béton armé soumis à la corrosion des aciers, Ph.D. thesis, Université Laval, Quebec, Canada, 2001.

[22] EuroLightCon document, BE96-3942/R3, 1999.

[23] DuraCrete, Duracrete Brite Euram III, Report No. Final report, Project BE95-1347, 2000.

[24] L. Tang and J. Gulikers, "On the mathematics of time-dependent apparent chloride diffusion coefficient in concrete," Cement and Concrete Research, vol. 37, pp. 589-595, 2007.

[25] L. Ying-Yu and W. Qui-Dong, "The mechanism of carbonation of mortars and the dependence of carbonation on pore structure," ACI-SP 100, Concrete Durability, 1915-1943, 1987. 
[26] V. Papadakis, C. Vayenas, and M. Fardis, "Fundamental modelling and experimental investigation of concrete carbonation," ACI Materials Journal, vol. 4, no. 88, pp. 363-373, 1991.

[27] CEB, "New approach to durability design: an example for a carbonation induced corrosion," Bulletin, vol. 238, 1997.

[28] R. Miragliotta, Modélisation des processus physico-chimiques de la carbonatation des bétons préfabriqués - prise en comptes des effets de paroi, Ph.D. thesis, Université de la Rochelle, La Rochelle, France, 2000.

[29] N. Hyvert, Application de l'approche probabiliste de la durabilité des produits préfabriqués en béton, Ph.D. thesis, Université de Toulouse III-Paul Sabatier, Toulouse, France, 2009.

[30] L. Nilsson, "Prediction models for chloride ingress and corrosion initiation in concrete structures," in Proceedings of the Nordic Mini Seminar-Fib TD 5.5 Meeting, Goteborg, Sweden, May 2001.

[31] H. S. Wong and N. R. Buenfeld, "Determining the watercement ratio, cement content, water content and degree of hydration of hardened cement paste: method development and validation on paste samples," Cement and Concrete Research, vol. 39, no. 10, pp. 957-965, 2009.

[32] G. Dubé, Grandeurs associées á la durabilité du béton, Association Française du Génie Civil, Paris, France, 2007.

[33] O. Braydi, P. Lafon, and R. Younes, "On the formulation of optimization problems under uncertainty in mechanical design," International Journal on Interactive Design and Manufacturing (IJIDeM), vol. 12, no. 48, pp. 1-13, 2018.

[34] M. H. François, "A decision-centric analysis of the sandia structural mechanics validation problem," in Proceedings of the 48th AIAA/ASME/ASCE/AHS/ASC Structures, Structural Dynamics, and Materials Conference, Palm Springs, CA, USA, May 2007.

[35] F. M. Hemez and Y. Ben-Haim, "Info-gap robustness for the correlation of tests and simulations of a non-linear transient," Mechanical Systems and Signal Processing, vol. 18, no. 6, pp. 1443-1467, 2004.

[36] P.-J. Lehmann, "Les fondements du libéralisme économique: Les 50 économistes á l'origine de la pensée libérale en France," ISTE, London, UK, Chapter Gustave de Molinari, 2017.

[37] B. Thauvin and N. Rouxel, Pathologies des ouvrages portuaires: méthodes d'investigation, Centre d'Etudes Techniques Maritimes et Fluviales, France, 2008.

[38] NTBuild492, "Concrete, mortar and cement based repair materials: chloride migration coefficient from non steady state migration experiments," NORDTEST, 1999.

[39] AFNOR, NF T01-021, 1974.

[40] K. K. Hansen, Sorption Isotherms-A Catalogue, The Technical University of Denmark, Kongens Lyngby, Denmark, Building Materials Laboratory, 1986.

[41] R. Harifidy, Transferts dans les milieux poreux réactifs non saturés:application à la cicatrisation de fissure dans les matériaux cimentaires par carbonatation (in french), Ph.D. thesis, University of Toulouse III-Paul Sabatier, Toulouse, France, 2010 